\title{
Phenylpropane as an Alternative Dearomatizing Unit of Indoles: Discovery of Inaequalisines A and B Using Substructure-Informed Molecular Networking
}

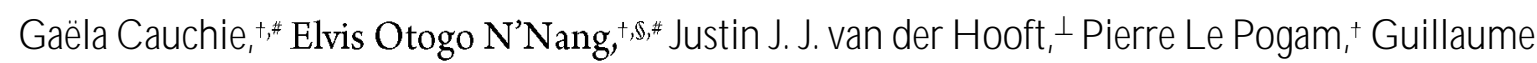
Bernadat, ${ }^{+}$J ean-François G allard, ${ }^{+}$B rice Kumulungui, ${ }^{\S}$ Pierre C hampy, ${ }^{+}$Erwan Poupon,${ }^{+}$and $M$ ehdi A. Beniddir*,+.

+Équipe "Chimie des Substances Naturelles" Université Paris-Saclay, CN RS, BioC IS, 5 rue J.-B. Clément, 92290 Châtenay-M alabry, France.

${ }^{\S}$ D epartment of Chemistry ( IN SAB), U niversité des Sciences et T echniques de M asuku, BP769 Franceville, Gabon.

${ }^{\perp}$ Bioinformatics Group, Wageningen U niversity, Wageningen, The N etherlands.

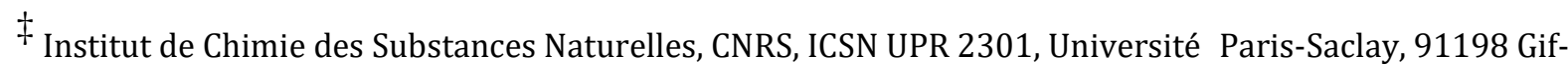
sur-Yvette, France.

mehdi.beniddir@universite-paris-saclay.fr 


\section{Summary:}

S1. Experimental section: $\quad 4$

$\begin{array}{ll}\text { General experimental procedures } & 4\end{array}$

$\begin{array}{ll}\text { Plant material } & 4\end{array}$

$\begin{array}{ll}\text { Extraction and isolation } & 4\end{array}$

Data dependent LC-ESI-HRMS² analysis, FBMN, and MS2LDA parameters 5

S2. $\quad$ Global molecular network $\quad 8$

S3. Molecular family A $\quad 10$

S4. Mass2Motif_1 in nine parent masses of molecular family A 11

S5. Computational methods 16

S6. Experimental ECD spectra of 1 and $2 \quad 18$

$\begin{array}{lll}\text { S7. } & \text { EIC of inaequalisine A (1) } m / z, 443.2676 & 19\end{array}$

S8. HRESIMS spectrum of inaequalisine A (1) 20

S9. $\quad{ }^{1} \mathrm{H}$ NMR spectrum $\left(600 \mathrm{MHz}, \mathrm{MeOH}-d_{4}\right)$ of Inaequalisine A (1) 21

S10. $\quad{ }^{13} \mathrm{C}$ NMR spectrum $\left(150 \mathrm{MHz}, \mathrm{MeOH}-d_{4}\right)$ of Inaequalisine A (1) 22

S11. COSY spectrum $\left(600 \mathrm{MHz}, \mathrm{MeOH}-d_{4}\right)$ of Inaequalisine A (1) 23

S12. HSQC spectrum (600 MHz, MeOH- $\left.d_{4}\right)$ of Inaequalisine A (1) 24

S13. HMBC spectrum (600 MHz, MeOH- $\left.d_{4}\right)$ of Inaequalisine A (1) 25

S14. ROESY spectrum (600 MHz, MeOH-d4) of inaequalisine A (1) 26

S15. EIC of inaequalisine B (2) $\mathrm{m} / z, 473.275$ from the alkaloid extract 27

S16. HRESIMS spectrum of inaequalisine B (2) 28

S17. ${ }^{1} \mathrm{H}$ NMR spectrum (600 MHz, MeOH- $\left.d_{4}\right)$ of inaequalisine B (2) 29

S18. Expanded views of ${ }^{1} \mathrm{H}$ NMR spectrum (600 MHz, MeOH- $\left.d_{4}\right)$ of inaequalisine B (2) 30

S19. ${ }^{13} \mathrm{C}$ NMR spectrum (150 MHz, MeOH- $\left.d_{4}\right)$ of inaequalisine B (2) 31

S20. COSY spectrum (600 MHz, MeOH- $\left.d_{4}\right)$ of inaequalisine B (2) 32

S21. HSQC spectrum $\left(600 \mathrm{MHz}, \mathrm{MeOH}-d_{4}\right)$ of inaequalisine B (2) 33

S22. $\mathrm{HMBC}$ spectrum $\left(600 \mathrm{MHz}, \mathrm{MeOH}-d_{4}\right)$ of inaequalisine B (2) 34

S23. ROESY spectrum (600 MHz, $\left.\mathrm{MeOH}-d_{4}\right)$ of inaequalisine B (2) 35 


\section{S1. Experimental section:}

\section{General experimental procedures}

The optical rotations were measured in the methanolic solution at $25{ }^{\circ} \mathrm{C}$ on a Polar 32 polarimeter. Ultraviolet (UV) spectra were measured on a Lightwave II+ WPA 7126 V. 1.6.1 spectrophotometer. CD spectra were measured at $25{ }^{\circ} \mathrm{C}$ on a JASCO J-810 spectropolarimeter. Infrared (IR) spectra were recorded with a Perkin-Elmer® type 257 spectrometer. Exact mass HRESIMS data were recorded using an Agilent 6530 AccurateMass QTOF mass spectrometer (Agilent Technologies, Santa Clara, CA, USA) in positive ion mode. ${ }^{1} \mathrm{H}$ and ${ }^{13} \mathrm{C}$ NMR spectra were recorded on a Bruker AM-600 (600 MHz) apparatus equipped with a microprobe TXI $1.7 \mathrm{~mm}$, using $\mathrm{MeOH}-\mathrm{d}_{4}$ as solvent. The solvent signals were used as references. Multiplicities are described by the following abbreviations: $s=$ singlet, $\mathrm{d}=$ doublet, $\mathrm{t}=$ triplet, $\mathrm{q}=$ quadruplet, brs = broad singlet, brd = broad doublet, $\mathrm{ddd}=$ doublet of doublet of doublets, $\mathrm{dq}=$ doublet of quadruplets, $\mathrm{dt}=$ doublet of triplets. Sunfire ${ }^{\circledR}$ preparative C18 columns $(150 \times 19 \mathrm{~mm}$, i.d. $5 \mu \mathrm{m}$, Waters $)$ were used for preparative HPLC separations with a Waters Delta Prep equipped with a binary pump (Waters 2525) and a UVvisible diode array detector (190-600 nm, Waters 2996). Silica 80 g Grace ${ }^{\circledR}$ cartridges were used for flash chromatography with an Armen Instrument - Spot Liquid Chromatography Flash apparatus. Chemicals and solvents were purchased from Sigma-Aldrich.

\section{Plant material}

The dry roots of Callichilia inaequalis Stapf was collected in Mondah forest, Gabon in January 2016. Botanical identification was confirmed by Prof. Henri Paul Bourobou Bourou and Mr. Raoul Niangadouma of the Institute of Pharmacopoeia and Traditional Medicine (IPHAMETRA) of Libreville. A herbarium voucher specimen (E.O.N 0014) was deposited at the National Herbarium of Gabon (Libreville).

\section{Extraction and isolation}

The dried and powdered roots of $C$. inaequalis $(1860 \mathrm{~g})$ was alkalinized with $\mathrm{NH}_{4} \mathrm{OH}$ $(25 \%)$ and extracted with EtOAc $(10 \mathrm{~L}$, room temperature, for $30 \mathrm{~h})$. The EtOAc crude extract was filtered under vacuum and concentrated by rotatory evaporation. This extract was 
submitted to liquid/liquid extraction with a solution of hydrochloric acid 1\% (1.5 L), followed by alkalinization of the aqueous fraction with concentrated $\mathrm{NH}_{4} \mathrm{OH}$ solution until $\mathrm{pH} 10$, and extraction of liberated alkaloids with EtOAc. The EtOAc fraction was reduced to dryness by rotatory evaporation at $35{ }^{\circ} \mathrm{C}$ yielding $2.53 \mathrm{~g}$ of an alkaloid extract. All this residue was fractionated by flash chromatography on Silica $40 \mathrm{~g}^{\text {Grace }}{ }^{\circledR}$ cartridge using a gradient of $\mathrm{CHCl}_{3}$ with increasing proportions of $\mathrm{MeOH}$ (100:0 to 0:100). The flow rate was set at 24 $\mathrm{mL} / \mathrm{min}$. The flash chromatography separation yielded 7 fractions according to their TLC profiles, which were analyzed by HPLC-QTOF-HRESIMS in order to localize the potential new compounds. The fractions F.6 and F.7 were selected for purification by preparative HPLC-UV using an Sunfire ${ }^{\circledR}$ preparative $C_{18}$ columns $(150 \times 19 \mathrm{~mm}$, i.d. $5 \mu \mathrm{m}$, Waters $)$ with a linear gradient elution of $\mathrm{MeOH}-\mathrm{H}_{2} \mathrm{O}(0.1 \%$ formic acid $)$. The flow rate was set to 17 $\mathrm{mL} / \mathrm{min}$ and UV absorbances were set at $254 \mathrm{~nm}$ and $280 \mathrm{~nm}$. Fraction F.6 (31.6 $\mathrm{mg}$ ) was purified with a preparative HPLC-UV using a gradient of $\mathrm{MeOH}-\mathrm{H}_{2} \mathrm{O}(0.1 \%$ formic acid $)$ (30\% to $60 \% \mathrm{MeOH}$ in $36 \mathrm{~min}$ ) and afforded ineaqualisine B (2) (1 mg). Fraction F.7 (45 mg) was purified with a preparative HPLC-UV using a gradient of $\mathrm{MeOH}-\mathrm{H}_{2} \mathrm{O}(0.1 \%$ formic acid) (35\% to $70 \% \mathrm{MeOH}$ in $41 \mathrm{~min}$ ) and afforded ineaqualisine $\mathrm{A}(\mathbf{1})(1 \mathrm{mg})$.

Inaequalisine $A$ (1): Yellow amorphous powder; $[\alpha]_{\mathrm{D}}^{24.0}+110.0\left(c 0.05, \mathrm{CH}_{2} \mathrm{Cl}_{2}\right)$.; IR $v_{\max }$ 3400, $1720 \mathrm{~cm}^{-1}$; UV $(\mathrm{MeOH}) \lambda_{\max }(\log \varepsilon) 254.7$ (2.42), 296.1 (3.3) nm; ${ }^{1} \mathrm{H}$ and ${ }^{13} \mathrm{C} \mathrm{NMR}$ data, see Table 1; HRMS (ESI) $m / z$ : [M] $]^{+}$Calcd for $\mathrm{C}_{29} \mathrm{H}_{35} \mathrm{~N}_{2} \mathrm{O}_{2}{ }^{+}$443.2693; Found 443.2669; The MS/MS spectrum was deposited in the GNPS spectral library under the identifier: CCMSLIB00005723369

Inaequalisine $B(2)$ : Yellow amorphous powder; $[\alpha]_{\mathrm{D}}{ }^{24.0}+82.7\left(\mathrm{c} 0.075, \mathrm{CH}_{2} \mathrm{Cl}_{2}\right)$; IR $v_{\max }$ 3400, $1720 \mathrm{~cm}^{-1}$; UV (MeOH) $\lambda_{\max }(\log \varepsilon) 288.8(2.42), 293.6(3.25) \mathrm{nm} ;{ }^{1} \mathrm{H}$ and ${ }^{13} \mathrm{C} \mathrm{NMR}$ data, see Table 1; HRMS (ESI) $m / z[M]^{+}$Calcd for $\mathrm{C}_{30} \mathrm{H}_{37} \mathrm{~N}_{2} \mathrm{O}_{3}{ }^{+}$473.2799; Found 473.2749; The MS/MS spectrum was deposited in the GNPS spectral library under the identifier: CCMSLIB00005723370

\section{Data dependent LC-ESI-HRMS ${ }^{2}$ analysis, FBMN, and MS2LDA parameters}

Data dependent LC-HRMS ${ }^{2}$ analyses. LC-ESI-HRMS ${ }^{2}$ analyses were achieved by coupling the LC system to a hybrid quadrupole time of-flight mass spectrometer Agilent 6530 
(Agilent Technologies, Massy, France) equipped with an ESI source, operating in positive-ion mode. Source parameters were set as followed: capillary temperature at $320{ }^{\circ} \mathrm{C}$, source voltage at $3500 \mathrm{~V}$, sheath gas flow rate at $10 \mathrm{~L} \cdot \mathrm{min}^{-1}$. The divert valve was set to waste for the first $3 \mathrm{~min}$. MS scans were operated in full-scan mode from $\mathrm{m} / \mathrm{z} 100$ to 1700 (0.1s scan time) with a mass resolution of 11000 at $\mathrm{m} / \mathrm{z}$ 922. MS1 scan was followed by $\mathrm{MS}^{2}$ scans of the three most intense ions above an absolute threshold of 5000 counts. Selected parent ions were fragmented with three collision energies fixed at 30,50 , and $70 \mathrm{eV}$ and an isolation window of $1.3 \mathrm{amu}$. Calibration solution, containing two internal reference masses (purine, $\mathrm{C}_{5} \mathrm{H}_{4} \mathrm{~N}_{4}$, $\mathrm{m} / \mathrm{z}$ 121.050873, and HP-921 [hexakis-(1H,1H,3H-tetrafluoropentoxy)phosphazene], $\mathrm{C}_{18} \mathrm{H}_{18} \mathrm{O}_{6} \mathrm{~N}_{3} \mathrm{P}_{3} \mathrm{~F}_{24}, \mathrm{~m} / z$ 922.0098). A permanent MS/MS exclusion list criterion was set to prevent oversampling of the internal calibrant.LC-UV and MS data acquisition and processing were performed using MassHunter Workstation software (Agilent Technologies, Massy, France).

Feature-Based Molecular Networking. The $\mathrm{MS}^{2}$ data files, related to the alkaloid extract and the fractions of the roots of $C$. inaequalis were converted from the .d (Agilent) standard data-format to .mzXML format using the MSConvert software, part of the ProteoWizard package. ${ }^{1}$ All .mzXML were then processed using MZmine 2 v52. ${ }^{2}$ The mass detection was realized keeping the noise level at 3.3E3 at MS1 and at 1E2 at MS2. The ADAP chromatogram builder was used using a minimum group size of scans of 2 , a group intensity threshold of 10000, a minimum highest intensity of 10000 and $\mathrm{m} / \mathrm{z}$ tolerance of $0.05 \mathrm{Da}$ (or 20 ppm). ${ }^{3}$ The ADAP wavelets deconvolution algorithm was used with the following standard settings: $\mathrm{S} / \mathrm{N}$ threshold $=100$, minimum feature height $=3000$, coefficient $/$ area threshold $=5$, Peak duration range 0.02 - $2 \mathrm{~min}$, RT wavelet range $0.02-0.3$. $\mathrm{MS}^{2}$ scans were paired using a $\mathrm{m} / \mathrm{z}$ tolerance range of $0.02 \mathrm{Da}$ and $\mathrm{RT}$ tolerance range of $1.0 \mathrm{~min}$. Isotopes were grouped using the isotopic peaks grouper algorithm with a $m / z$ tolerance of $0.05 \mathrm{Da}$ (or $15 \mathrm{ppm}$ ) and a RT tolerance of $0.3 \mathrm{~min}$. Peak alignment was performed using the join aligner module $(\mathrm{m} / \mathrm{z}$ tolerance $=0.05 \mathrm{Da}$ (or $15 \mathrm{ppm}$ ), weight for $m / z=1$, weight for RT $=1$, absolute RT tolerance $0.5 \mathrm{~min})$. The peak list was gap-filled with the same RT and $\mathrm{m} / \mathrm{z}$ range gap filler module $(\mathrm{m} / \mathrm{z}$ tolerance of $10 \mathrm{ppm}$ ). The gap-filled peak list was filtered to keep only rows with MS2 features. The .mgf and .csv (for RT and areas) files were exported using the dedicated "Export/Submit to GNPS/FBMN" option. The following parameters were used for this task: Merge MS/MS experimental (across sample, weighted average, sum intensities, mass 
deviation $=0.001 \mathrm{Da}$ or $5 \mathrm{ppm}$, Cosine threshold $=0 \%$, Peak count threshold $=20 \%$, isolation window offset $=0$, isolation window width $=1.3 \mathrm{Da}$ ). See further documentation at https://ccms-ucsd.github.io/GNPSDocumentation/featurebasedmolecularnetworking-withmzmine2/. The raw data files related to the LC-MS/MS analysis of the fractions were deposited on the public MassIVE repository under the accession number: MSV000085647.

Molecular Networking parameters. A molecular network was created using the online FBMN workflow (version release_20) at GNPS $^{4}$ (http://gnps.ucsd.edu) with a parent mass tolerance of $0.02 \mathrm{Da}$ and an MS/MS fragment ion tolerance of 0.02 Da. A network was then created where edges were filtered to have a cosine score above 0.6 and more than 6 matched peaks. Further edges between two nodes were kept in the network if and only if each of the nodes appeared in each other's respective top 10 most similar nodes. The spectra in the network were then searched against GNPS spectral libraries. All matches kept between network spectra and library spectra were required to have a score above 0.7 and at least 6 matched peaks. The molecular networking data were analyzed and visualized using Cytoscape (ver. 3.6.0). ${ }^{5}$

MS2LDA Unsupervised Substructure Annotation. The fragmentation spectra were mined for co-occurring fragments and neutral losses using the latent Dirichlet allocation algorithm $^{6}$ on the MS2LDA Web app. ${ }^{7}$ The following parameters were used for this task: isolation_window (0.5), min_ms2_int (500), n_its (1000), K (60), ms2_bin (0.05 Da), zero MotifDB. The results of the MS2LDA annotation are publicly available at the following link: http://ms2lda.org/basicviz/toggle_public/1341/. The inspection and the annotation of the Mass2Motifs were realized on the MS2LDA.org Web app. 


\section{S2. Global molecular network}

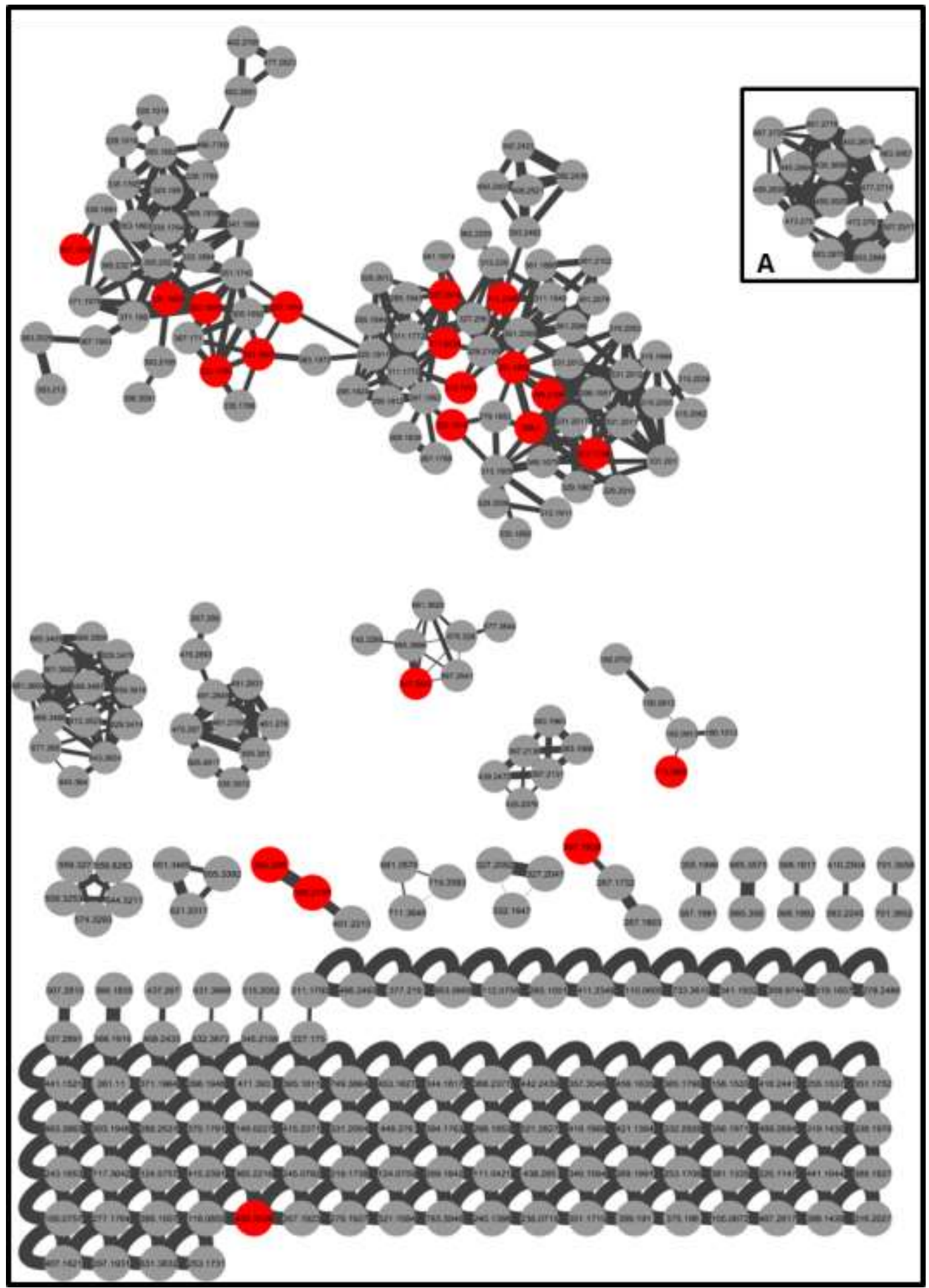

Figure S2: Molecular network of the root alkaloid extract of Callichilia inaequalis. A: cluster with targeted nodes for isolation. (this network is accessible at the following address: https://gnps.ucsd.edu/ProteoSAFe/status.jsp?task=0ab25ae94a0b40a49d1dd0d03903da7e) 
Table S2: Dereplicated compounds from the GNPS library

\begin{tabular}{|c|c|c|c|}
\hline Compound & Library & $\begin{array}{l}\text { Matching } \\
\text { score }\end{array}$ & Comment \\
\hline harman & Massbank & 0.88 & Not described in Callichilia genus \\
\hline corynantheidal & MIADB & 0.78 & Not described in Callichilia genus \\
\hline $\begin{array}{c}19,20- \\
\text { dihydrousambarensine }\end{array}$ & MIADB & 0.75 & Not described in Callichilia genus \\
\hline $\begin{array}{c}14,15 \\
\text { dehydrovincamine }\end{array}$ & MIADB & 0.93 & Not described in Callichilia genus \\
\hline $\begin{array}{c}10- \\
\text { hydroxygeissoschizol }\end{array}$ & MIADB & 0.74 & Not described in Callichilia genus \\
\hline corynantheidol & MIADB & 0.81 & Not described in Callichilia genus \\
\hline c-fluorocurarine & MIADB & 0.72 & Not described in Callichilia genus \\
\hline cinchonamine-HCl & MIADB & 0.71 & Not described in Callichilia genus \\
\hline tabersonine & MIADB & 0.96 & Not described in Callichilia genus \\
\hline criophylline & MIADB & 0.90 & Not described in Callichilia genus \\
\hline geissoschizine & MIADB & 0.73 & Not described in Callichilia genus \\
\hline geissoschizoline & MIADB & 0.75 & Not described in Callichilia genus \\
\hline ibogaine & MIADB & 0.82 & Not described in Callichilia genus \\
\hline ibogamine & MIADB & 0.85 & Not described in Callichilia genus \\
\hline iboxygaine & MIADB & 0.77 & Not described in Callichilia genus \\
\hline methuenine & MIADB & 0.71 & Not described in Callichilia genus \\
\hline mitrinermine & MIADB & 0.97 & Not described in Callichilia genus \\
\hline pericyclivine & MIADB & 0.84 & Not described in Callichilia genus \\
\hline tabernanthine & MIADB & 0.76 & Not described in Callichilia genus \\
\hline $\begin{array}{c}\text { 8-amino-6- } \\
\text { methoxyquinoline }\end{array}$ & Massbank EU & 0.80 & Not described in Callichilia genus \\
\hline
\end{tabular}



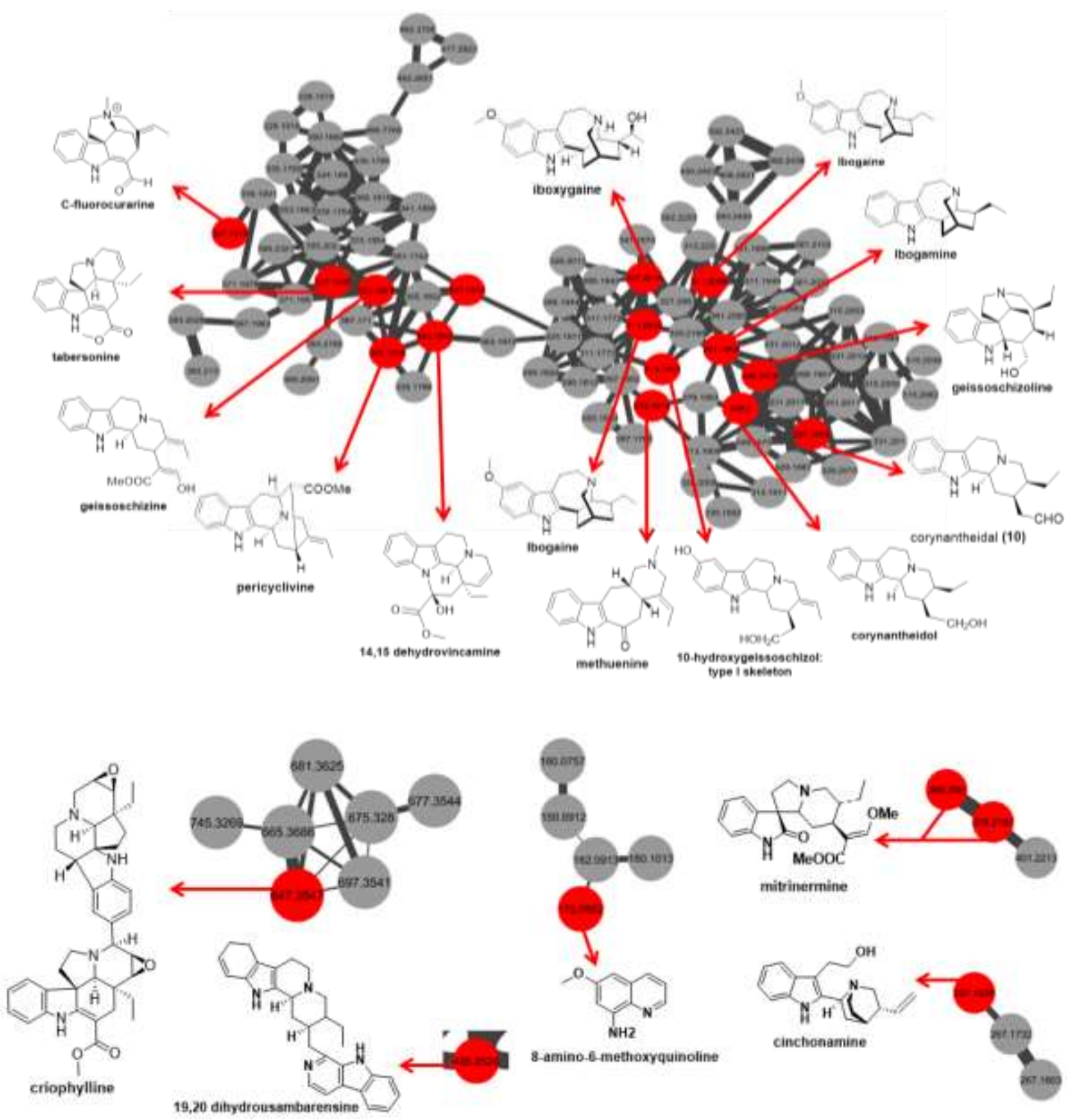

S3. Molecular family A 


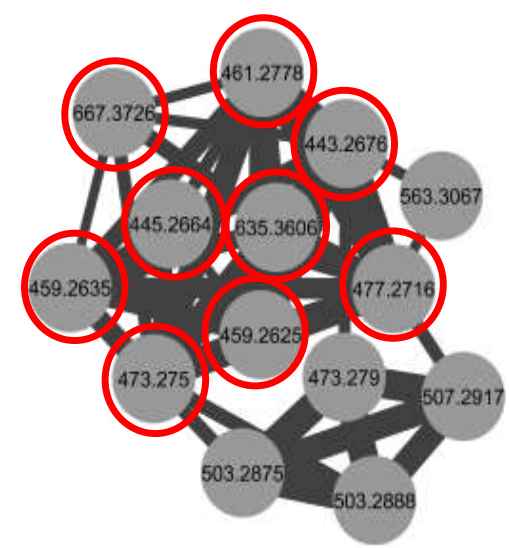

Figure S3: molecular family A

S4. Mass2Motif_1 in nine parent masses of molecular family A
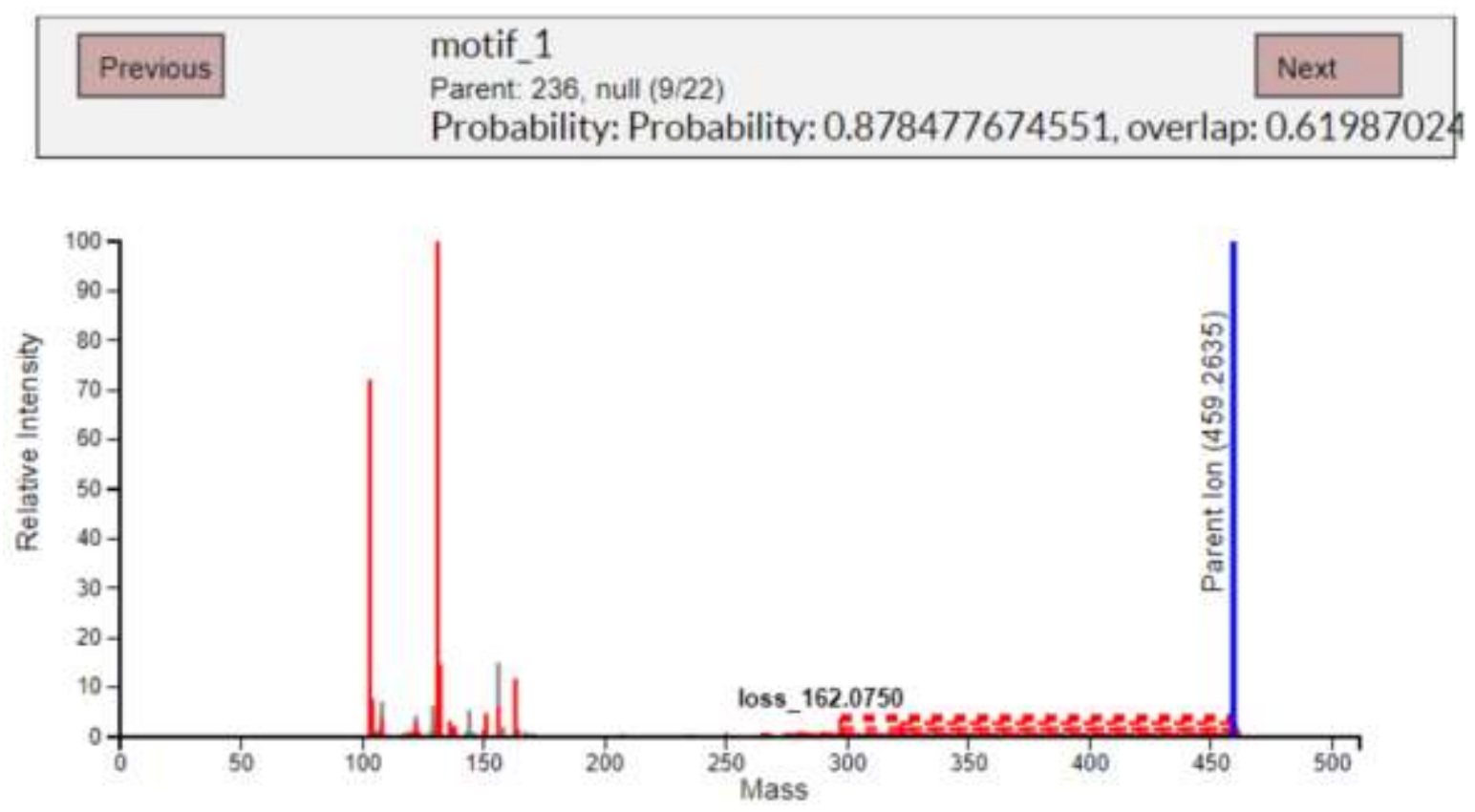

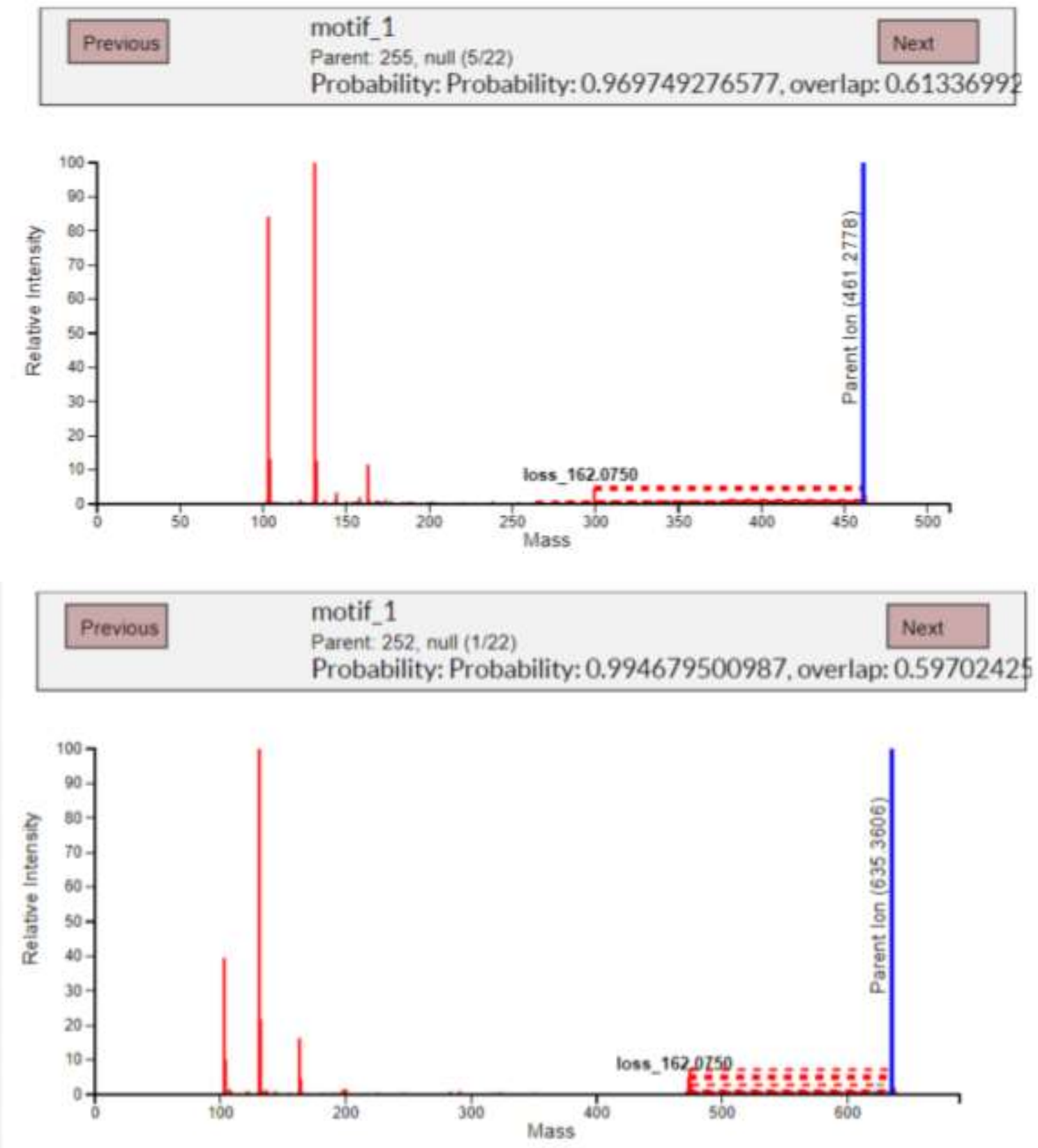
Probability: Probability: 0.978572399298 , overlap: 0.63878015

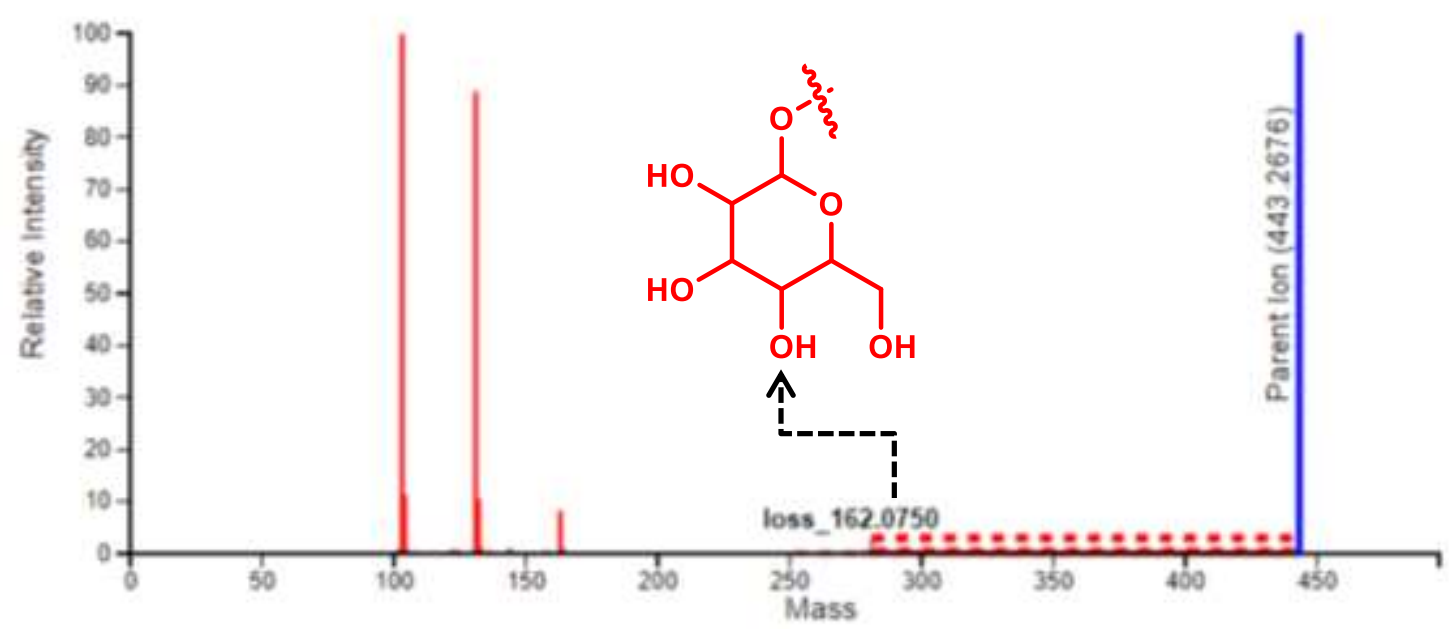

\section{Previous}

motif_1

Parent. 272, null (6/22)

Next

Probability: Probability: 0.969197447415 , overlap: 0.62379616

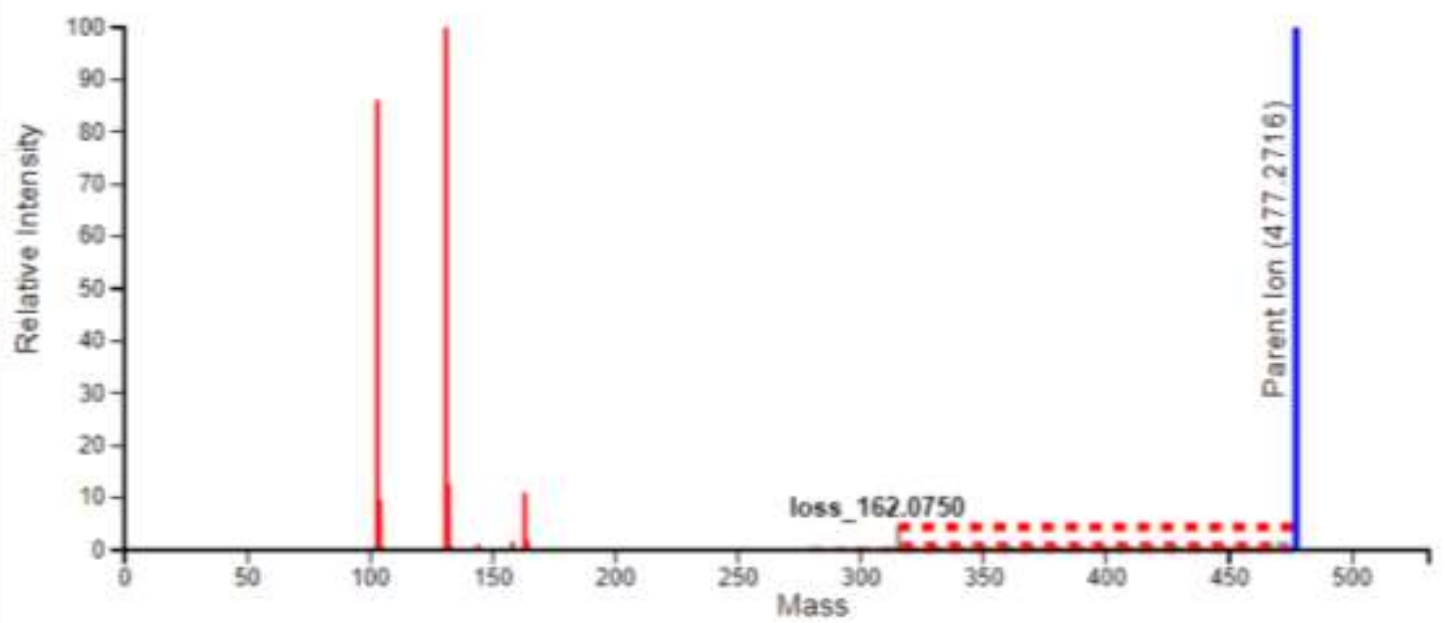


Previous motif_1

Parent: 203, null (2/22)

Probability: Probability: 0.984957309075 , overlap: 0.74341572

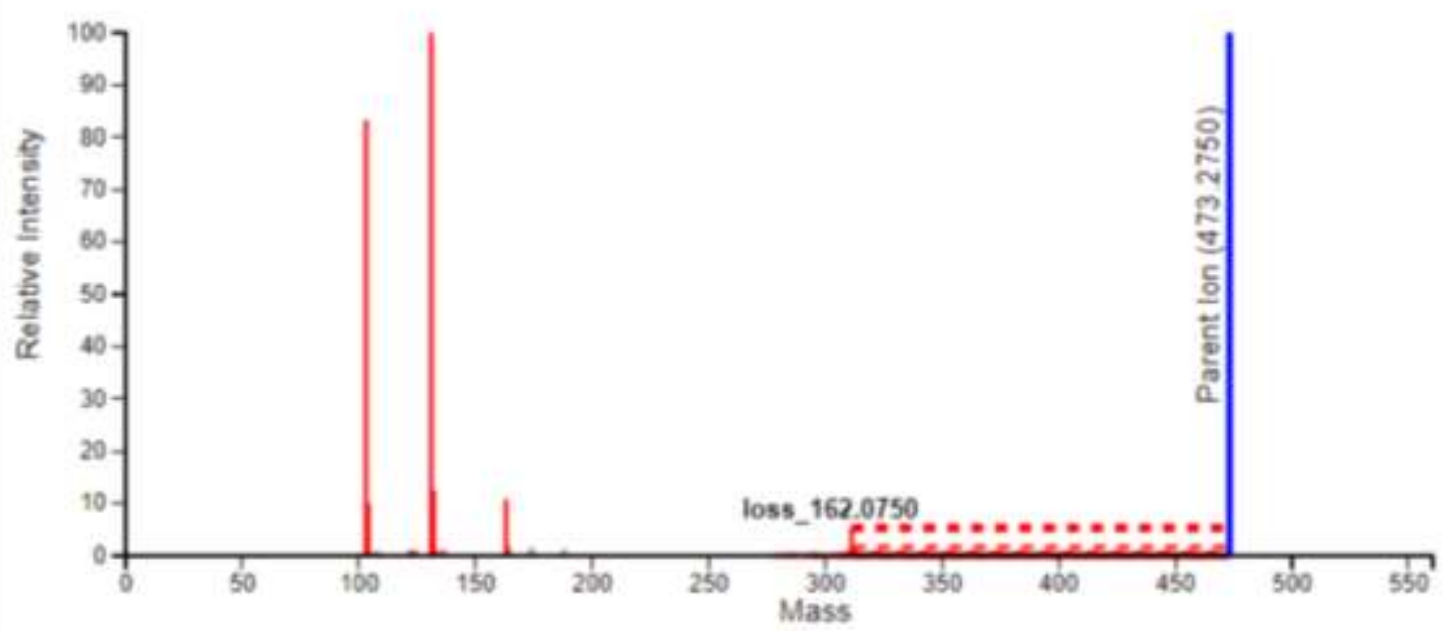

Previous motif_1

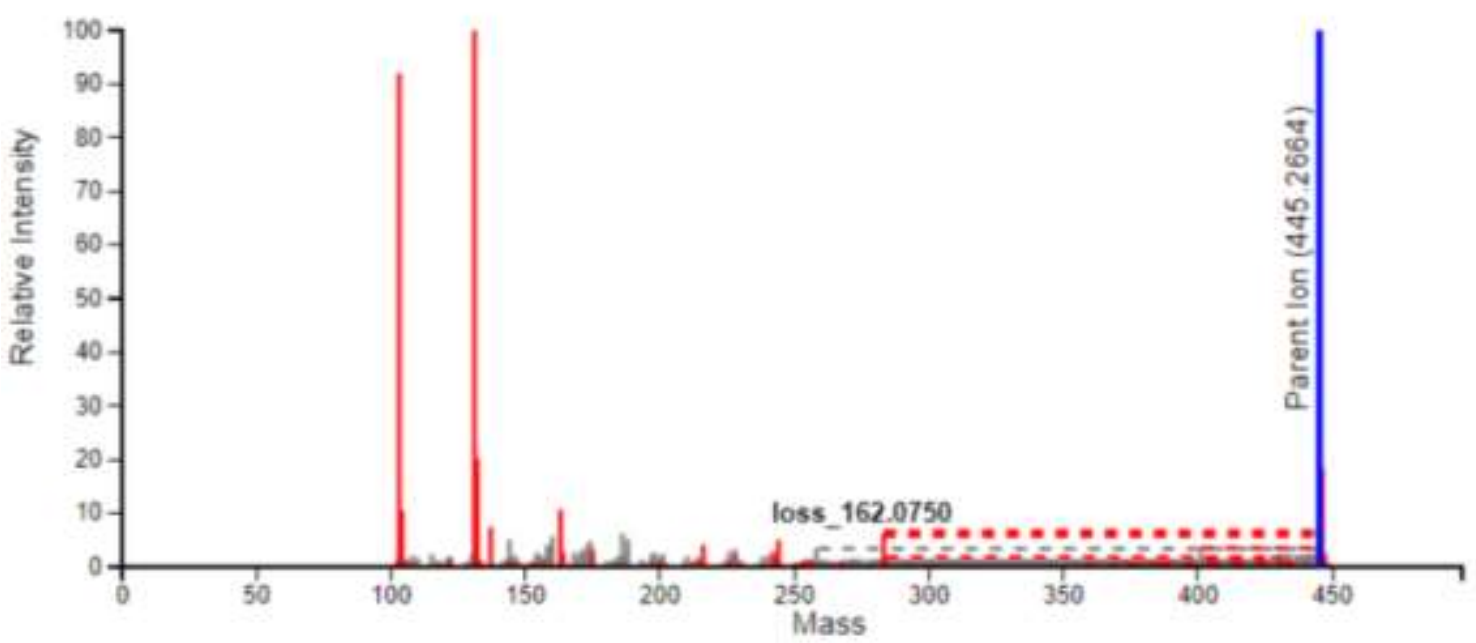




\begin{tabular}{|ll|}
\hline Previous & motif_1 14, null (7/22) \\
& Parent: 14t \\
& Probability: Probability: 0.964382736441, overlap: 0.4977890 \$
\end{tabular}
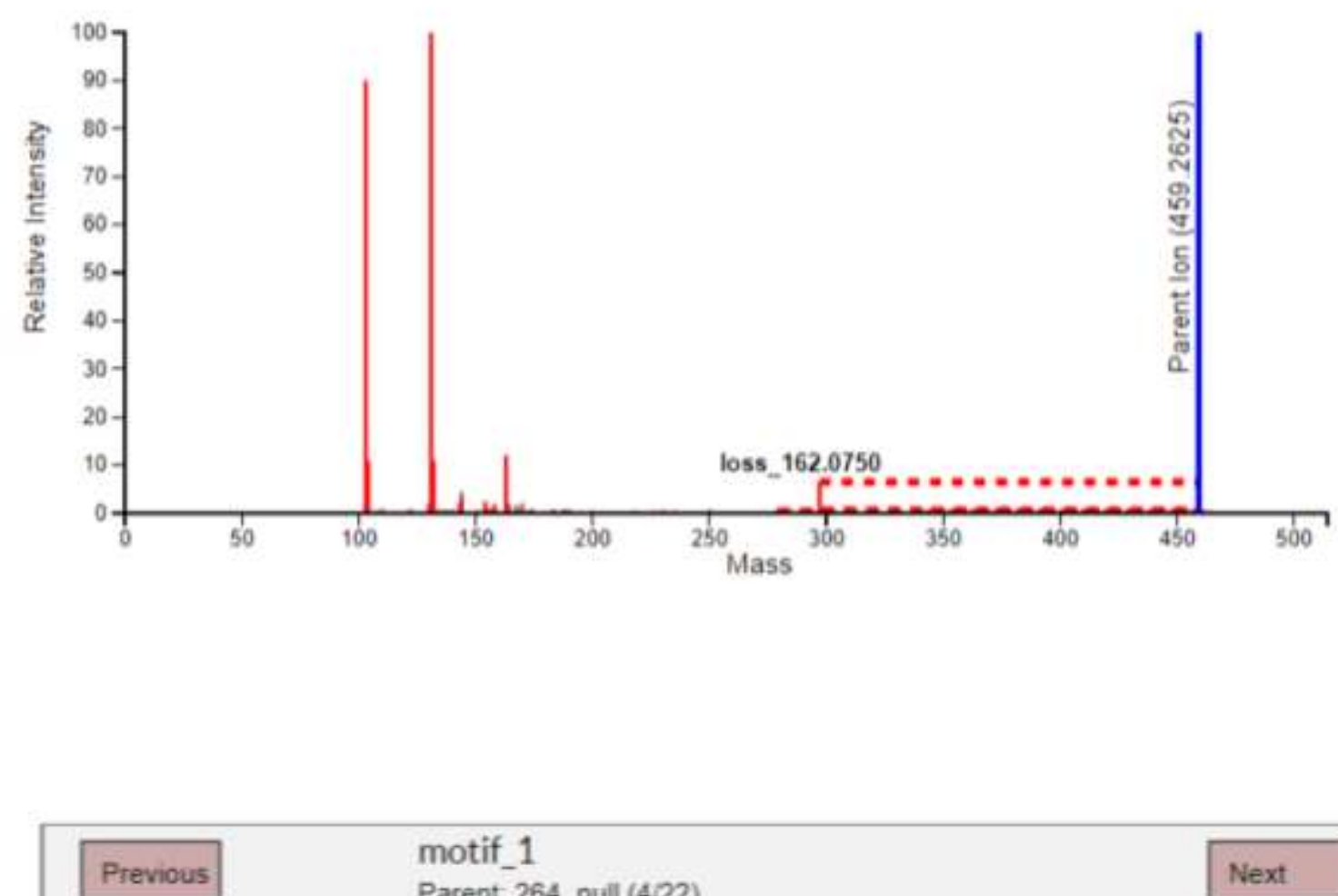

motif_1

Parent 264 , null (4/22)

Next

Probability: Probability: 0.972447207269, overlap:0.60852064

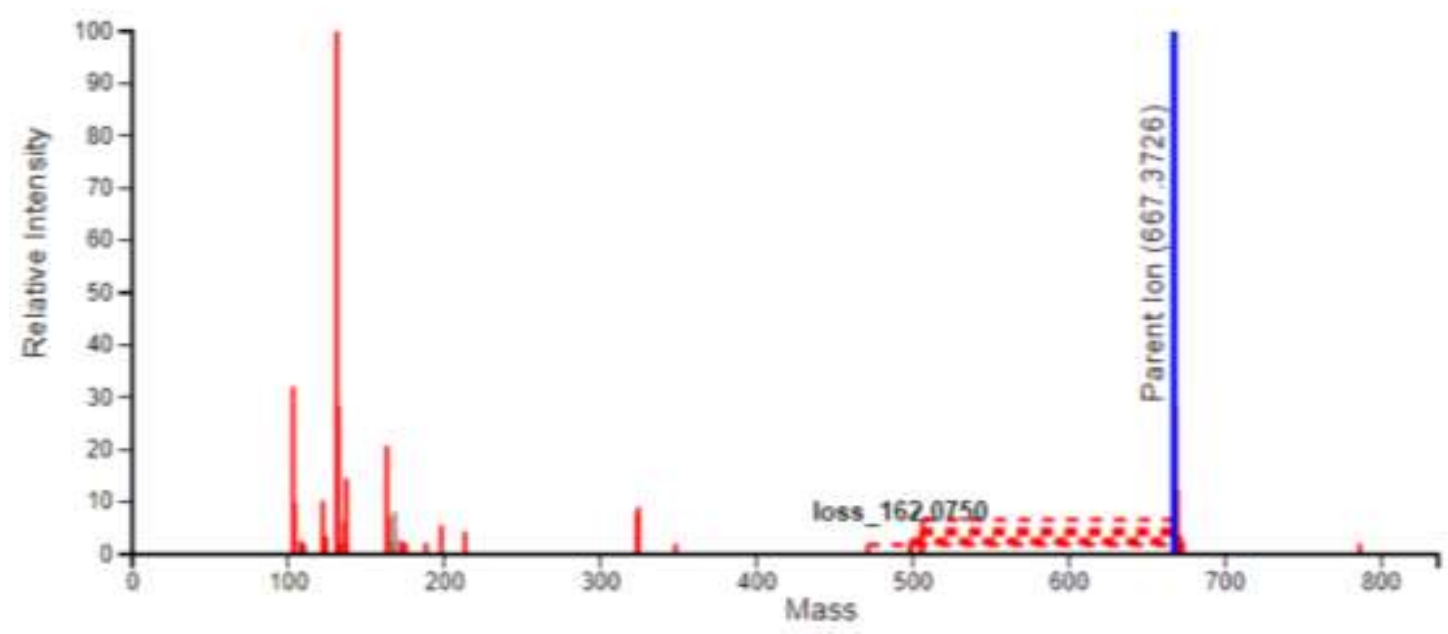




\section{S5. Computational methods}

The lowest energy conformer of compound $\mathbf{1}$ was fully optimized in vacuo and without constraint using $\mathrm{DFT}^{8,}{ }^{9}$ with the hybrid Becke-3-parameter-Lee-Yang-Parr ${ }^{10}{ }^{11}$ exchangecorrelation functional and the $6-31 \mathrm{G}^{*}$ basis, ${ }^{12}$ as implemented in the Gaussian 16 revB.01 software package. ${ }^{13}$ Upon geometrical optimization convergence, a frequency calculation within the harmonic approximation was conducted at the same level of theory and local minima were characterized by the absence of imaginary frequency. TDDFT at the same level of theory was then employed to predict energies as well as rotational strengths of the first 60 electronic transitions. The UCSF Chimera v1.11 ${ }^{14}$ software package was used for the depiction of the most stable conformer of compound 1. ECD spectrum envelope was then calculated using SpecDis v1.71 ${ }^{15}$ using sigma/gamma value of $0.2 \mathrm{eV}$ and a shift of $+8 \mathrm{~nm}$ and rendered using Gnuplot v5.2. ${ }^{16}$

Electronic energy (B3LYP): -1385.86313600 Ha.

Lowest frequency: $11.137 \mathrm{~cm}^{-1}$.

Free enthalpy: $-1385.331211 \mathrm{Ha}$.

Coordinates of the lowest energy conformer of 1 found at the B3LYP/6-31G* level

$\begin{array}{rrrrr}1 & C & -4.720137 & -4.267732 & -0.504163 \\ 2 & \mathrm{C} & -4.008561 & -3.550759 & 0.649849 \\ 3 & \mathrm{C} & -3.896238 & -2.007616 & 0.535663 \\ 4 & \mathrm{C} & -5.262815 & -1.370699 & 0.398983 \\ 5 & \mathrm{C} & -5.502603 & -0.346362 & -0.422562 \\ 6 & \mathrm{C} & -4.449821 & 0.287528 & -1.290161 \\ 7 & \mathrm{C} & -3.154906 & -1.452816 & 1.776008 \\ 8 & \mathrm{C} & -2.973953 & 0.067739 & 1.705357 \\ 9 & \mathrm{C} & -2.457100 & 0.707445 & 0.400079 \\ 10 & \mathrm{~N} & -3.054111 & -0.125007 & -0.902049 \\ 11 & \mathrm{C} & -2.065439 & 0.221673 & -1.987723 \\ 12 & \mathrm{C} & -0.701478 & 0.118533 & -1.324449 \\ 13 & \mathrm{C} & -3.051938 & -1.623737 & -0.679544 \\ 14 & \mathrm{C} & -0.880917 & 0.776223 & 0.071607 \\ 15 & \mathrm{C} & 0.001816 & 0.083207 & 1.155910 \\ 16 & \mathrm{C} & 1.476898 & 0.036368 & 0.856853 \\ 17 & \mathrm{C} & 2.121882 & -1.083679 & 0.481630 \\ 18 & \mathrm{C} & 3.544660 & -1.267990 & 0.191852 \\ 19 & \mathrm{C} & 4.502377 & -0.240798 & 0.358160 \\ 20 & \mathrm{C} & 5.835950 & -0.473801 & 0.063007 \\ 21 & \mathrm{O} & 6.863238 & 0.424577 & 0.183829 \\ 22 & \mathrm{C} & 6.579266 & 1.719755 & 0.695122 \\ 23 & \mathrm{C} & 6.257100 & -1.740397 & -0.411142 \\ 24 & \mathrm{O} & 7.561613 & -1.959983 & -0.697883 \\ 25 & \mathrm{C} & 5.321450 & -2.755381 & -0.573643 \\ 26 & \mathrm{C} & 3.981211 & -2.517559 & -0.271148\end{array}$




$\begin{array}{rrrrr}27 & \mathrm{C} & -0.652258 & 2.280975 & -0.039338 \\ 28 & \mathrm{C} & 0.508591 & 2.999459 & -0.322517 \\ 29 & \mathrm{C} & 0.449450 & 4.396210 & -0.381762 \\ 30 & \mathrm{C} & -0.761273 & 5.064530 & -0.179628 \\ 31 & \mathrm{C} & -1.939877 & 4.353752 & 0.063722 \\ 32 & \mathrm{C} & -1.854436 & 2.966293 & 0.123631 \\ 33 & \mathrm{~N} & -2.920304 & 2.056088 & 0.311908 \\ 34 & \mathrm{H} & -4.812874 & -5.334398 & -0.278322 \\ 35 & \mathrm{H} & -4.171685 & -4.188941 & -1.449749 \\ 36 & \mathrm{H} & -5.729470 & -3.875091 & -0.667366 \\ 37 & \mathrm{H} & -2.998809 & -3.964509 & 0.775556 \\ 38 & \mathrm{H} & -4.538721 & -3.764679 & 1.587035 \\ 39 & \mathrm{H} & -6.063754 & -1.769990 & 1.018289 \\ 40 & \mathrm{H} & -6.497051 & 0.084560 & -0.509527 \\ 41 & \mathrm{H} & -4.477344 & 1.378243 & -1.232881 \\ 42 & \mathrm{H} & -4.580901 & 0.008784 & -2.343514 \\ 43 & \mathrm{H} & -2.191394 & -1.968467 & 1.865317 \\ 44 & \mathrm{H} & -3.715915 & -1.686894 & 2.688140 \\ 45 & \mathrm{H} & -2.311922 & 0.407441 & 2.507892 \\ 46 & \mathrm{H} & -3.951137 & 0.520607 & 1.906790 \\ 47 & \mathrm{H} & -2.282485 & 1.245754 & -2.302671 \\ 48 & \mathrm{H} & -2.216221 & -0.451820 & -2.835175 \\ 49 & \mathrm{H} & 0.056684 & 0.638389 & -1.912815 \\ 50 & \mathrm{H} & -0.367843 & -0.919936 & -1.239314 \\ 51 & \mathrm{H} & -2.019673 & -1.948698 & -0.545915 \\ 52 & \mathrm{H} & -3.435296 & -2.065131 & -1.603229 \\ 53 & \mathrm{H} & -0.158819 & 0.600561 & 2.110442 \\ 54 & \mathrm{H} & -0.357642 & -0.944827 & 1.283624 \\ 55 & \mathrm{H} & 2.028289 & 0.962349 & 0.999139 \\ 56 & \mathrm{H} & 1.529125 & -1.995440 & 0.378778 \\ 57 & \mathrm{H} & 4.196236 & 0.729932 & 0.731000 \\ 58 & \mathrm{H} & 6.164091 & 1.661931 & 1.709034 \\ 59 & \mathrm{H} & 7.532346 & 2.249530 & 0.721111 \\ 60 & \mathrm{H} & 5.880323 & 2.257970 & 0.042211 \\ 61 & \mathrm{H} & 8.046872 & -1.137353 & -0.506331 \\ 62 & \mathrm{H} & 5.658743 & -3.722464 & -0.931699 \\ 63 & \mathrm{H} & 3.259858 & -3.320736 & -0.398652 \\ 64 & \mathrm{H} & 1.450296 & 2.489946 & -0.497679 \\ 65 & \mathrm{H} & 1.351187 & 4.963527 & -0.589715 \\ 66 & \mathrm{H} & -0.794158 & 6.148838 & -0.226573 \\ 67 & \mathrm{H} & -2.887557 & 4.868383 & 0.193890 \\ 68 & \mathrm{H} & -3.652709 & 2.326140 & 0.958367\end{array}$


S6. Experimental ECD spectra of 1 and 2

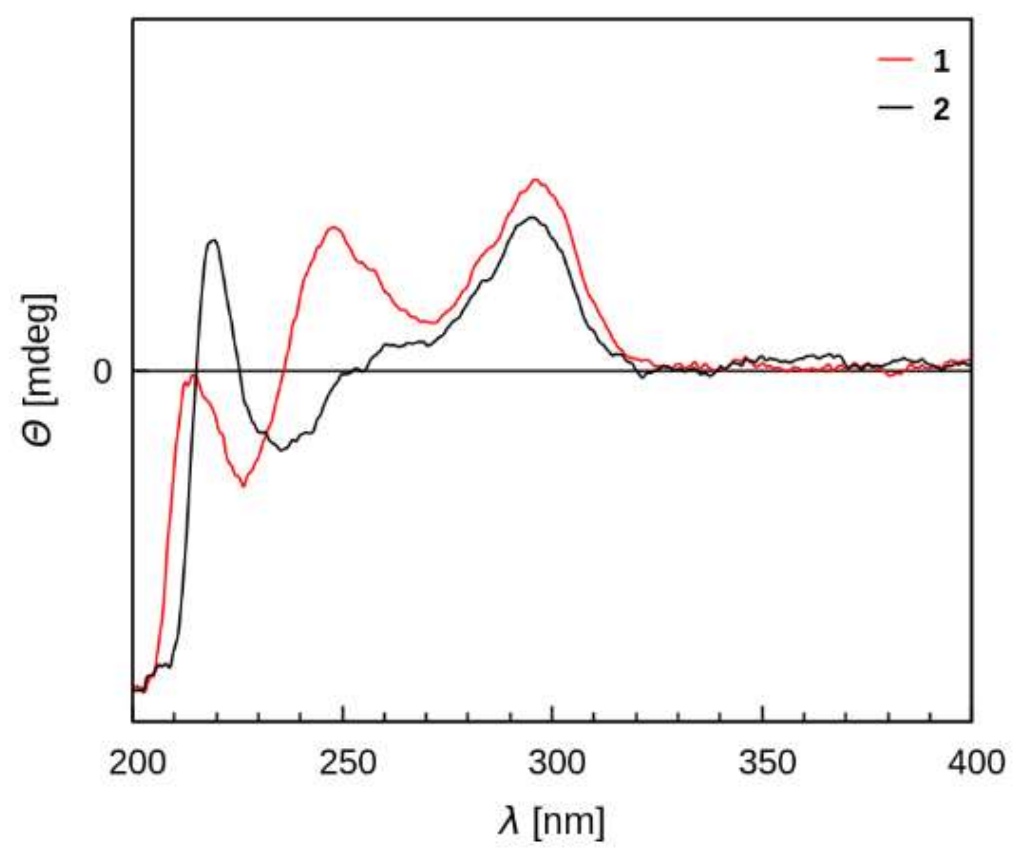

Experimental ECD spectra of $\mathbf{1}$ (red curve) and $\mathbf{2}$ (black curve) (in $\mathrm{MeOH}$ ) 
S7. $\quad$ EIC of inaequalisine A (1) $m / z$ 443.2676

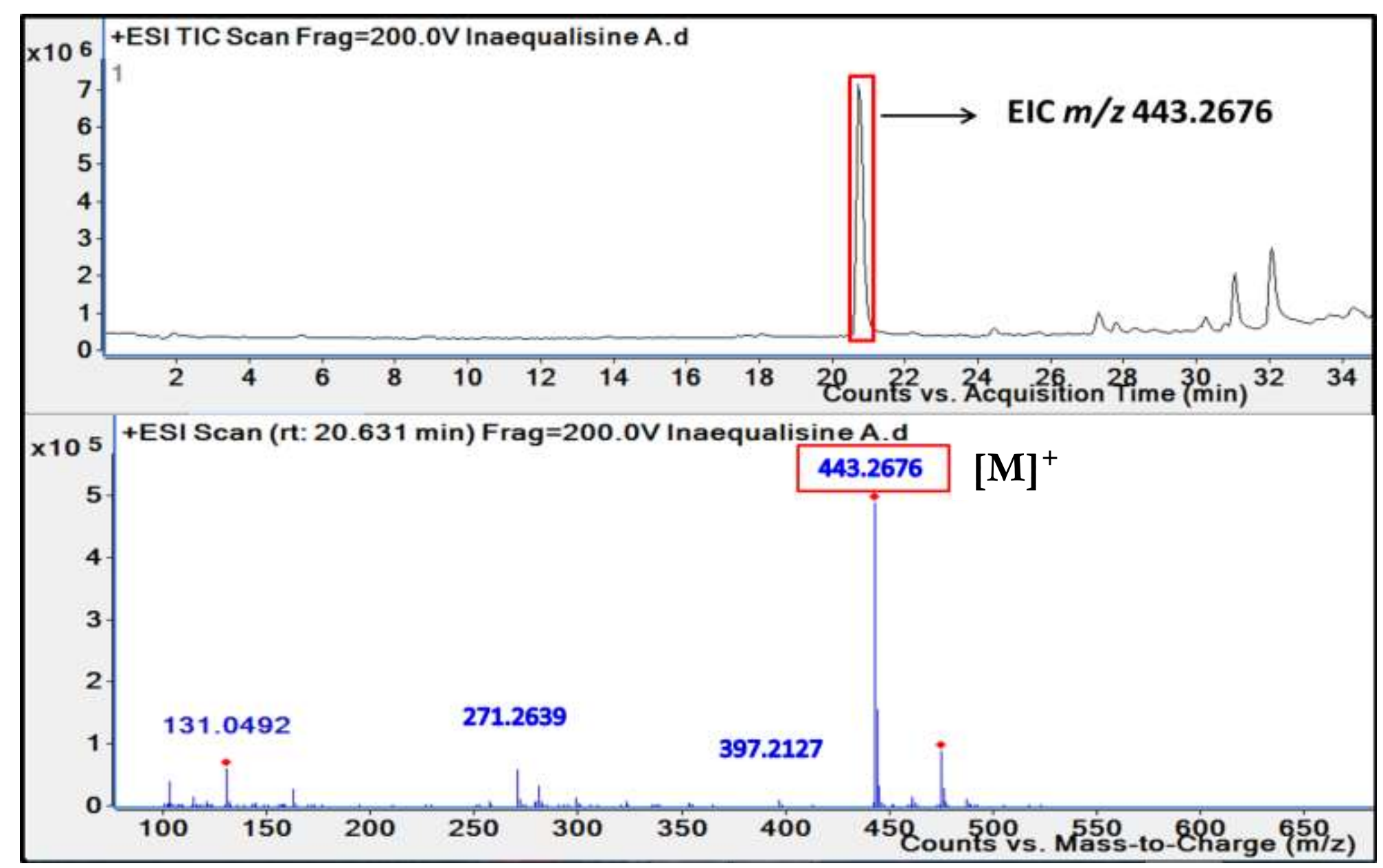

Sunfire ${ }^{\circledR} \mathrm{C}_{18}(150 \times 2.1 \mathrm{~mm})$; i.d. $3.5 \mu \mathrm{m}$, Waters $(5 / 95: 100 / 0) \mathrm{MeOH} / \mathrm{H}_{2} \mathrm{O}+0.1 \%$ formic acid. Flow rate: $0.25 \mathrm{~mL} / \mathrm{min}$. Injection volume: $5 \mu \mathrm{L}$. Concentration: $1 \mathrm{mg} / \mathrm{mL}$. 
S8. HRESIMS spectrum of inaequalisine A (1)

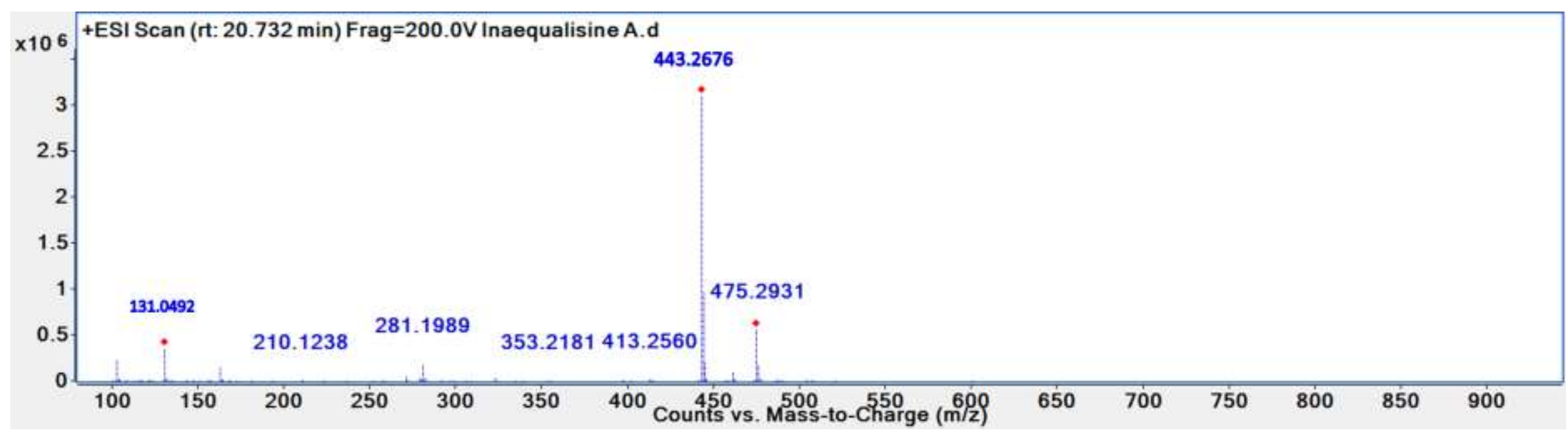


S9. $\quad{ }^{1} \mathrm{H}$ NMR spectrum (600 MHz, MeOH- $\left.d_{4}\right)$ of Inaequalisine A (1)

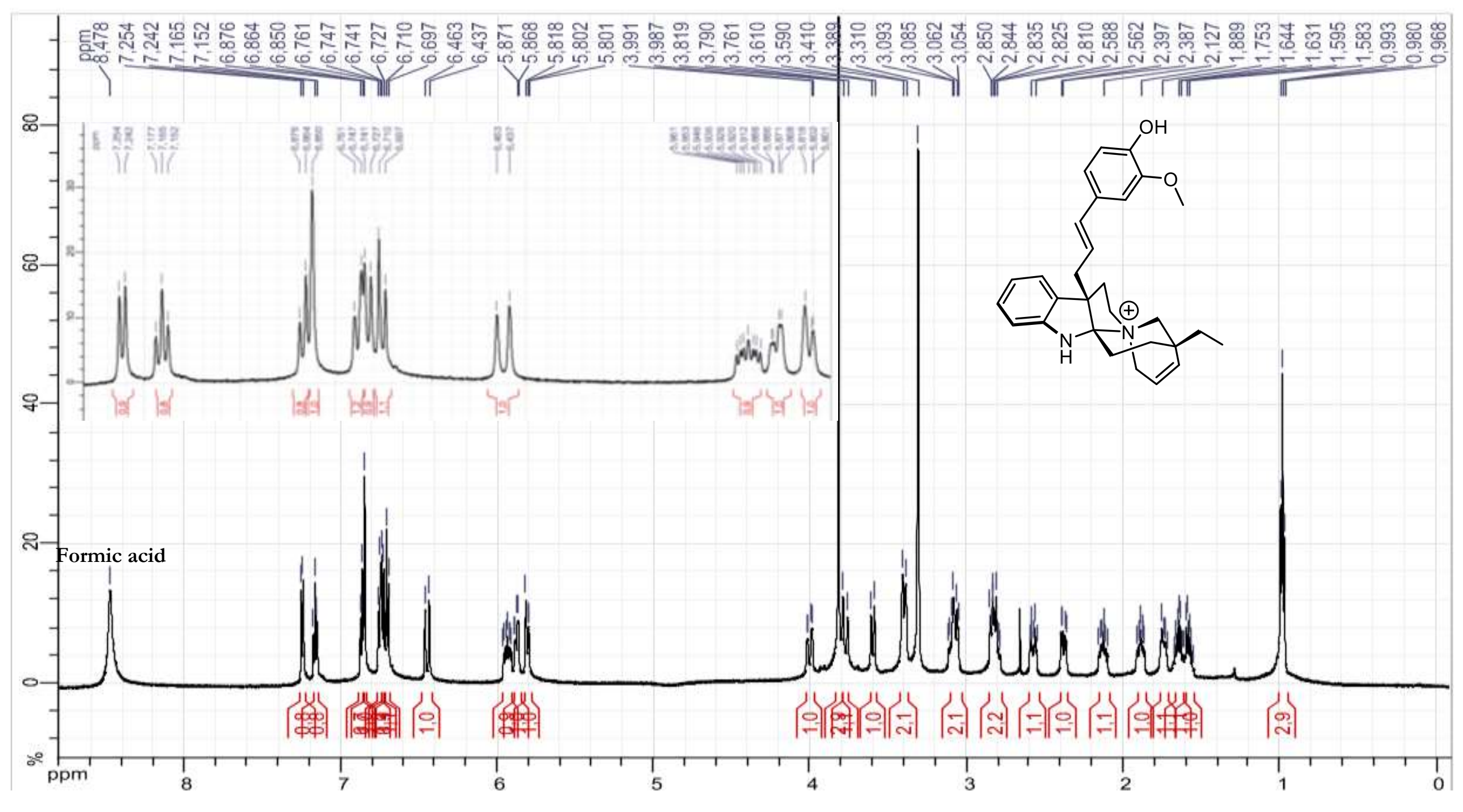


S10. ${ }^{13} \mathrm{C}$ NMR spectrum (150 MHz, MeOH- $\left.d_{4}\right)$ of Inaequalisine A (1)

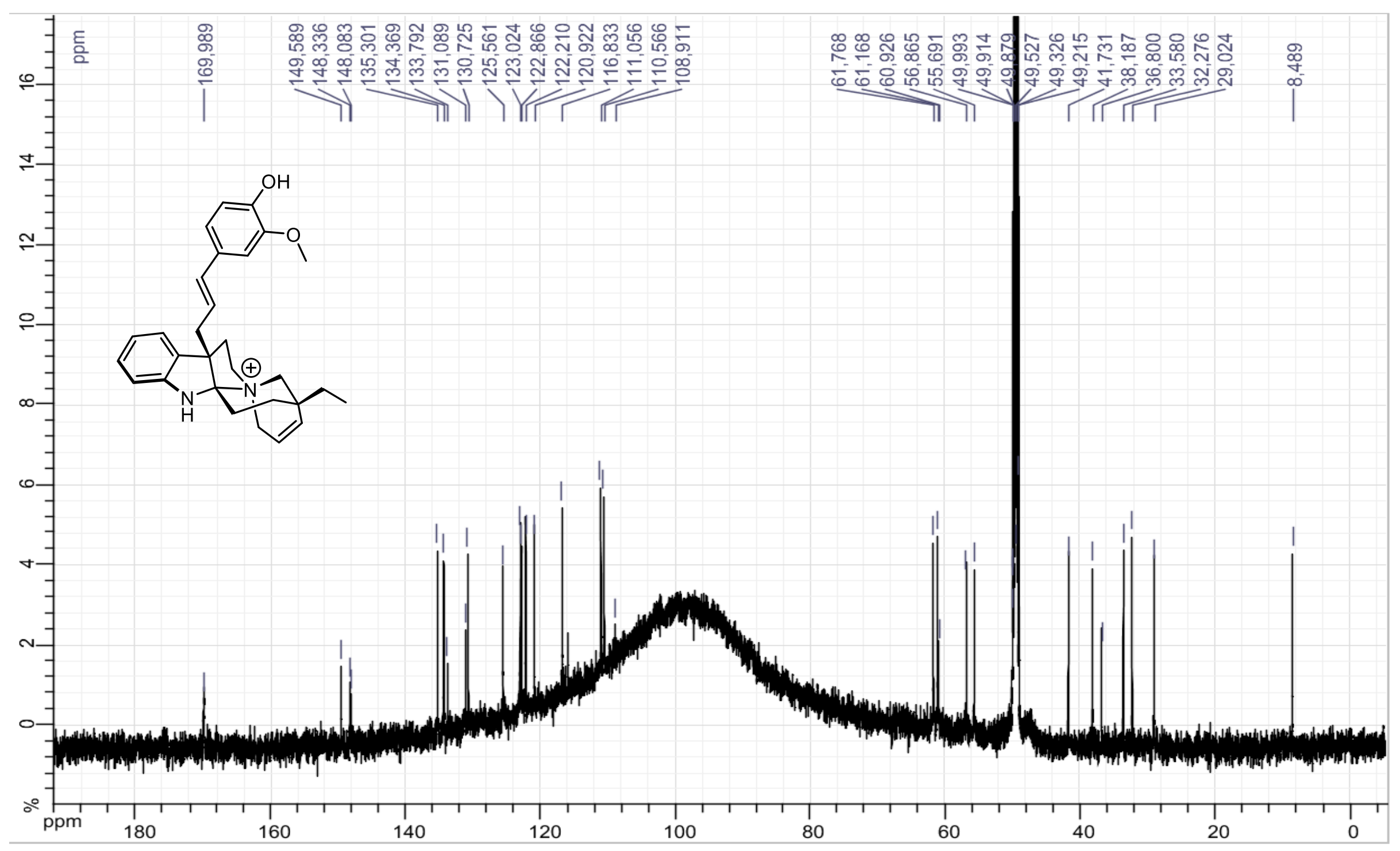


S11. COSY spectrum (600 MHz, MeOH- $\left.d_{4}\right)$ of Inaequalisine A (1)

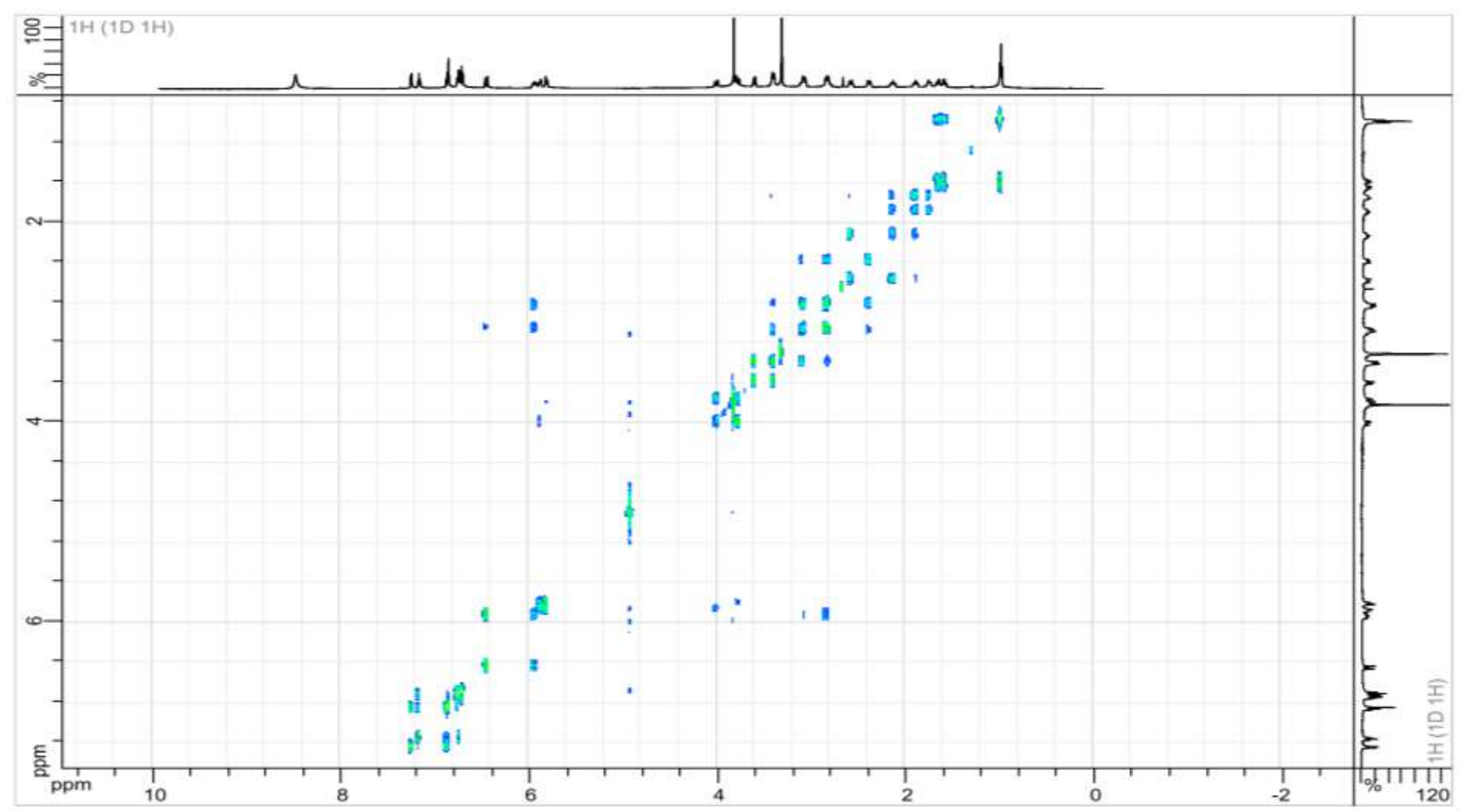


S12. HSQC spectrum (600 MHz, MeOH- $\left.d_{4}\right)$ of Inaequalisine A (1)

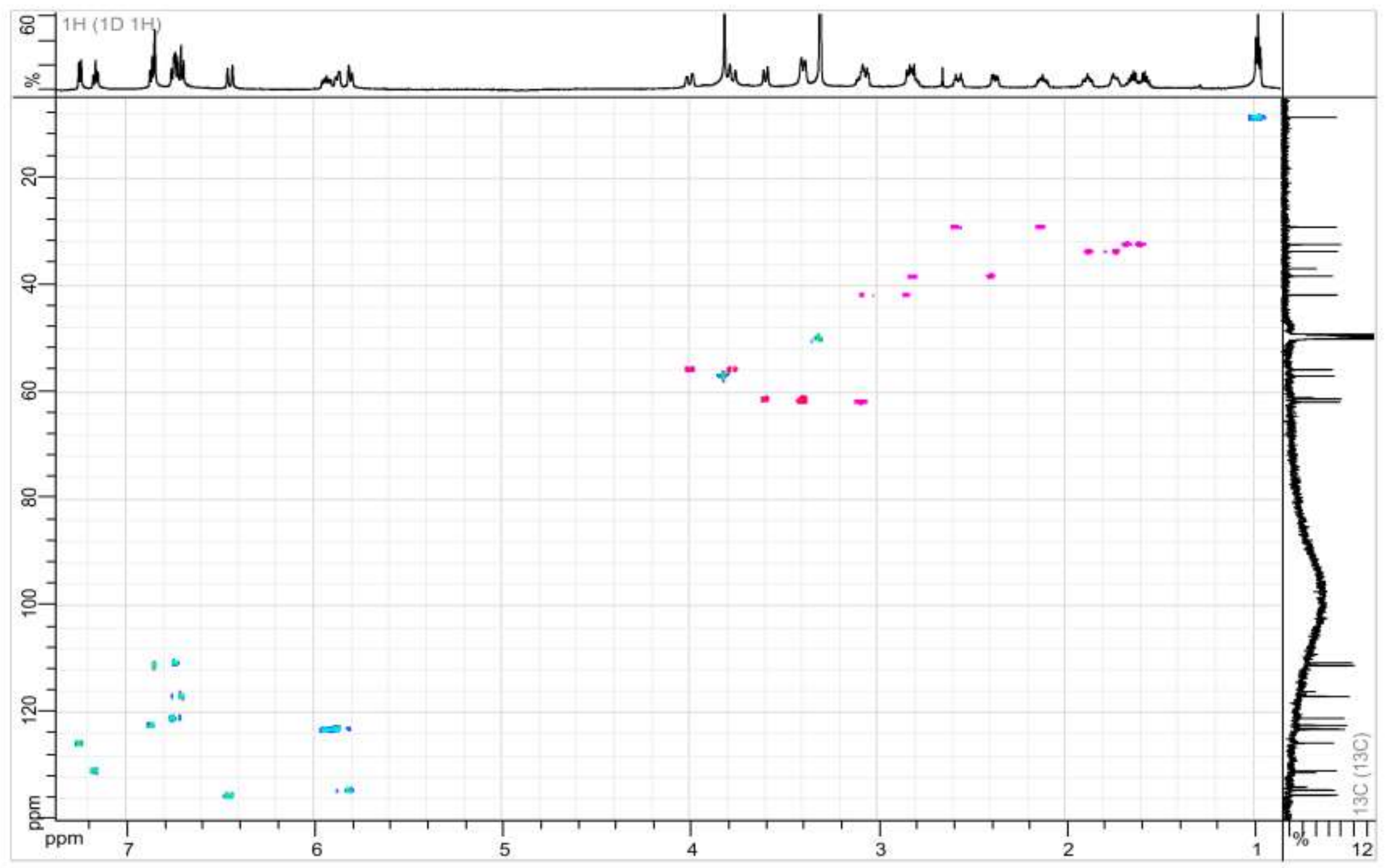

24 
S13. HMBC spectrum (600 MHz, MeOH- $\left.d_{4}\right)$ of Inaequalisine A (1)

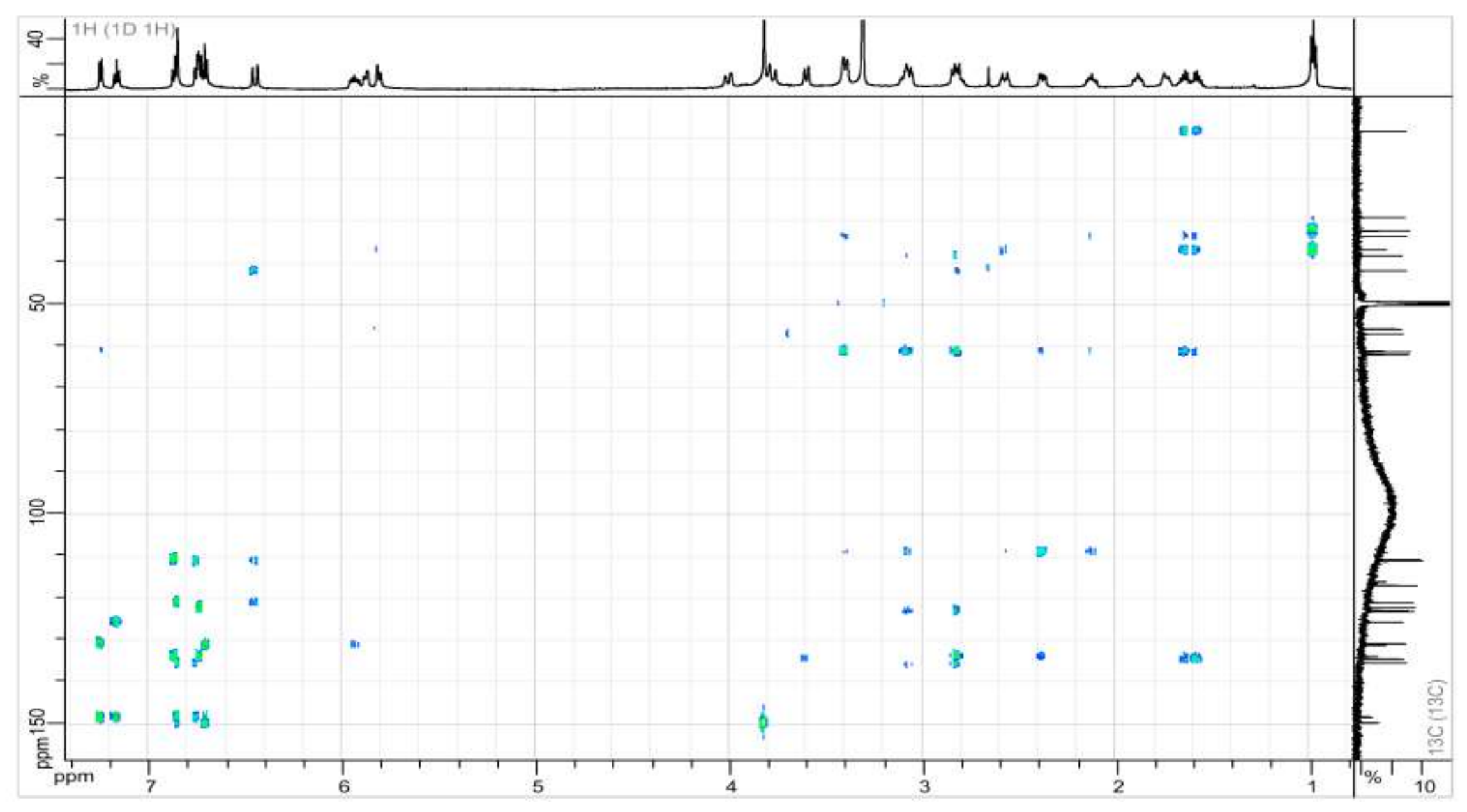


S14. ROESY spectrum (600 MHz, MeOH- $\left.d_{4}\right)$ of inaequalisine A (1)

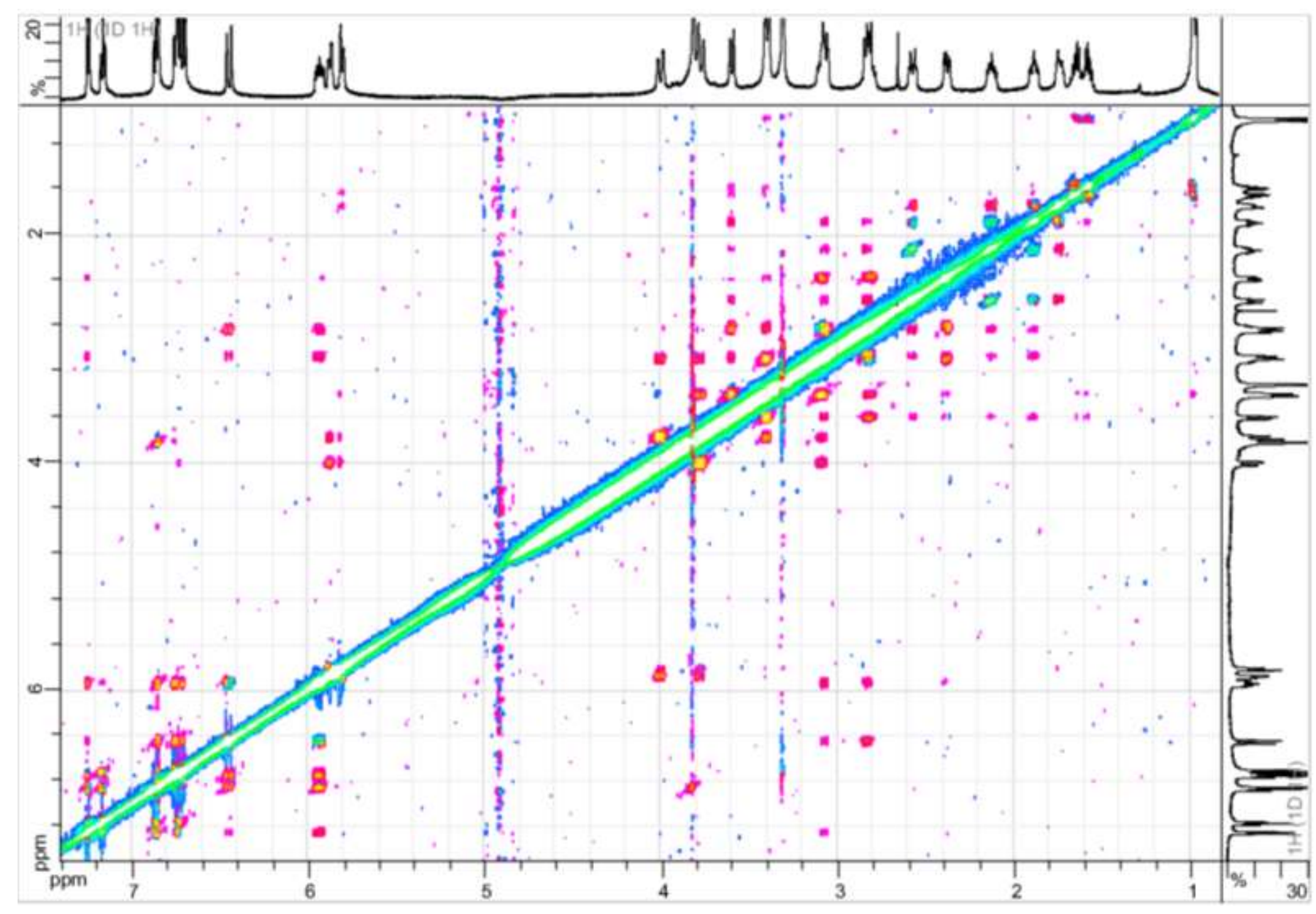


S15. EIC of inaequalisine B (2) $\mathrm{m} / \mathrm{z} \mathbf{4 7 3 . 2 7 5}$ from the alkaloid extract

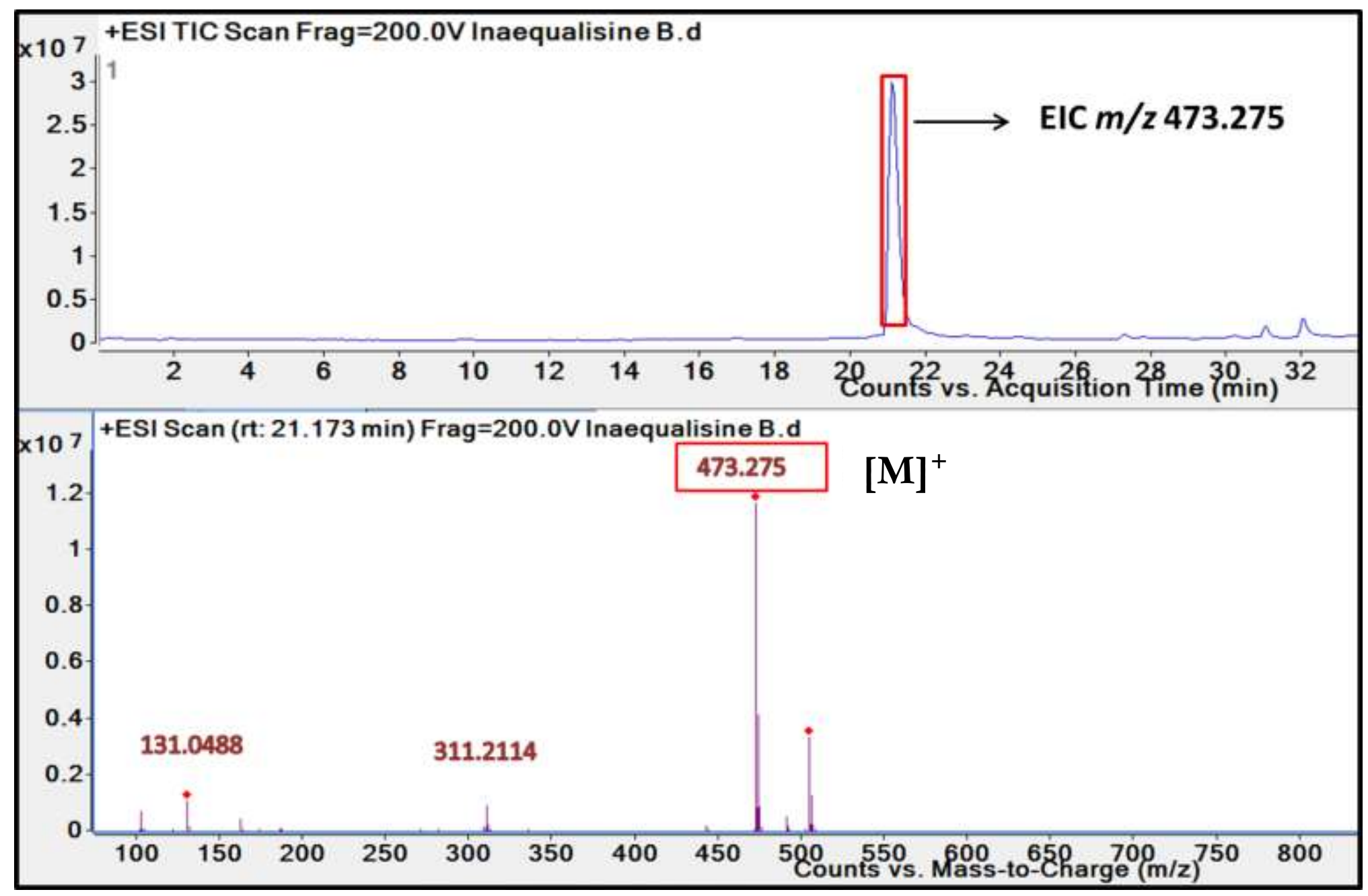

Sunfire ${ }^{\circledR} \mathrm{C}_{18}(150 \times 2.1 \mathrm{~mm})$; i.d. $3.5 \mu \mathrm{m}$, Waters $(5 / 95: 100 / 0) \mathrm{MeOH} / \mathrm{H}_{2} \mathrm{O}+0.1 \%$ formic acid. Flow rate: $0.25 \mathrm{~mL} / \mathrm{min}$. Injection volume: $5 \mu \mathrm{L}$. Concentration: $1 \mathrm{mg} / \mathrm{mL}$. 
S16. HRESIMS spectrum of inaequalisine B (2)

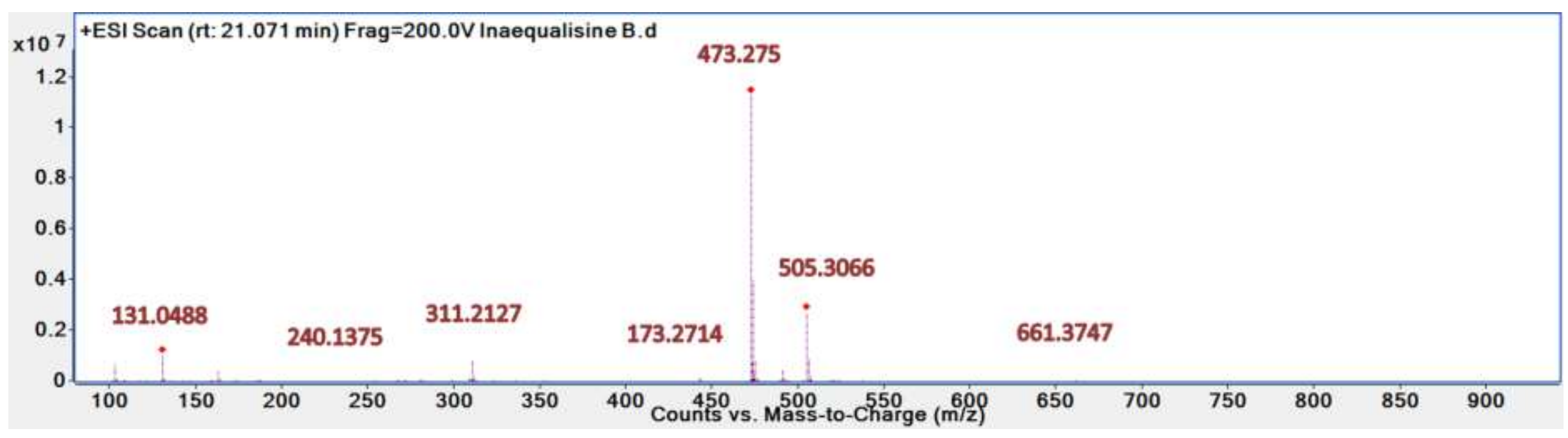


S17. $\quad{ }^{1} \mathrm{H}$ NMR spectrum $\left(600 \mathrm{MHz}, \mathrm{MeOH}-d_{4}\right)$ of inaequalisine $\mathrm{B}(2)$

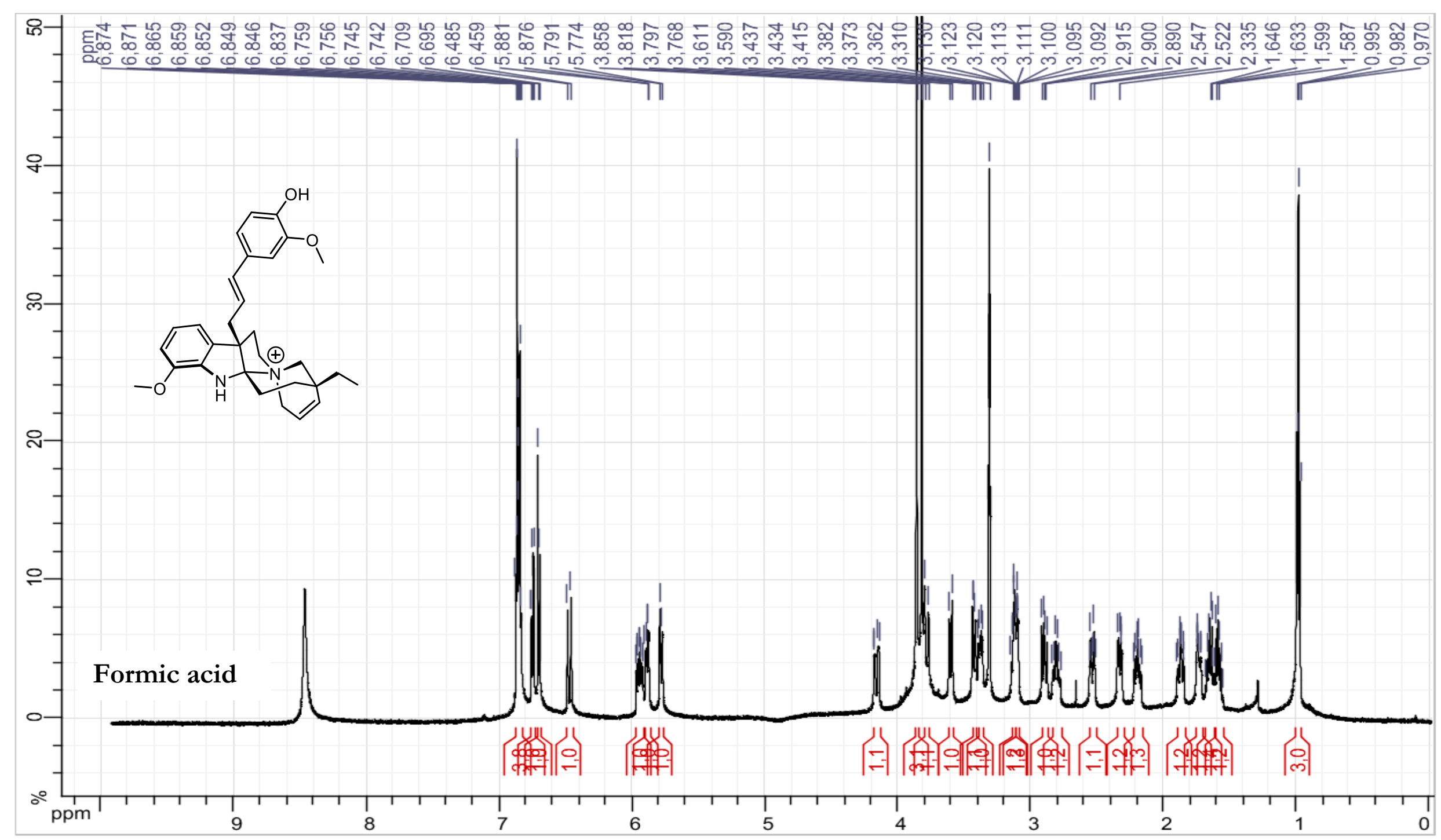


S18. Expanded views of ${ }^{1} \mathrm{H}$ NMR spectrum (600 MHz, MeOH-d $)$ of inaequalisine B (2)

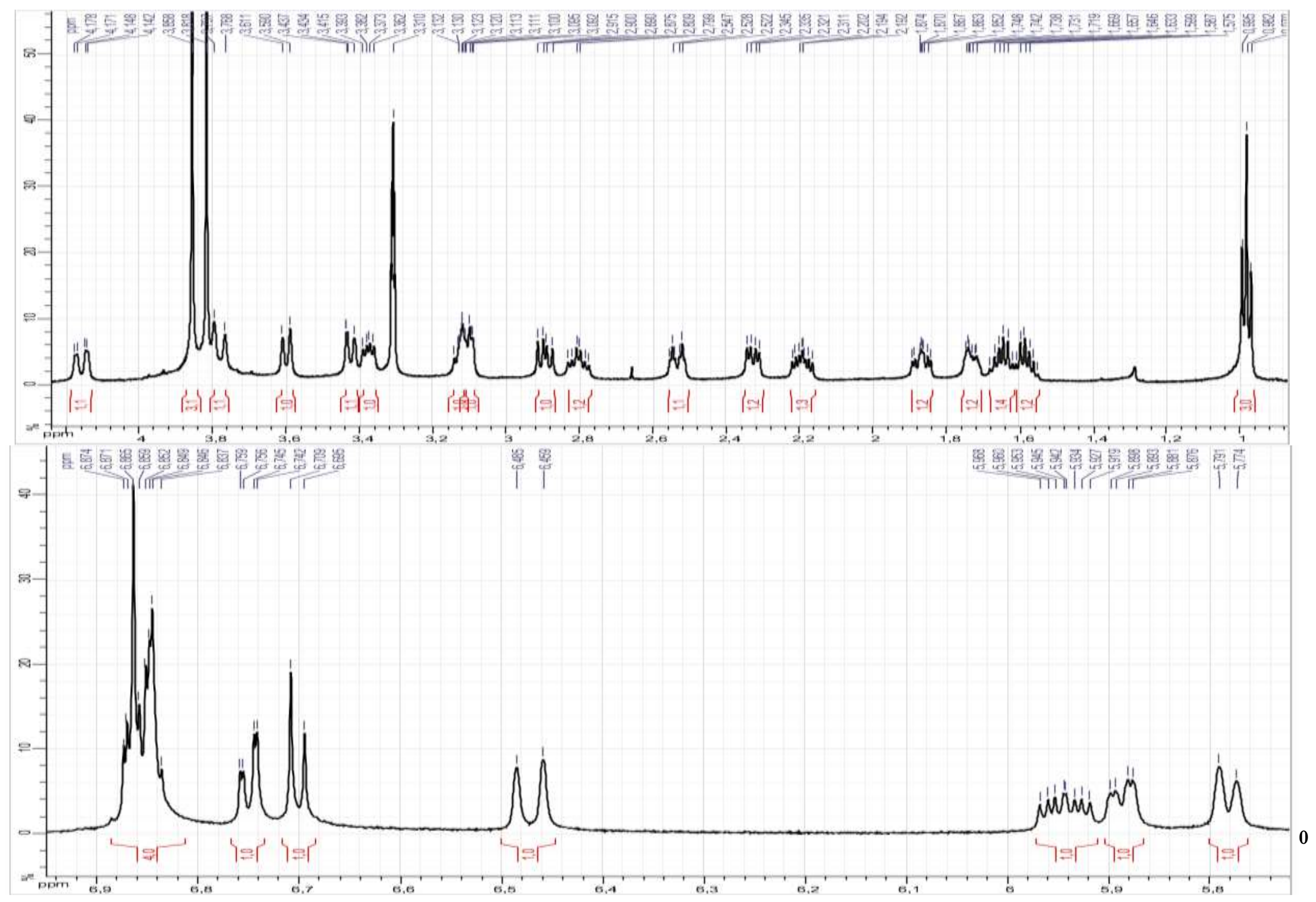


S19. $\quad{ }^{13} \mathrm{C}$ NMR spectrum (150 MHz, MeOH- $\left.d_{4}\right)$ of inaequalisine B (2)

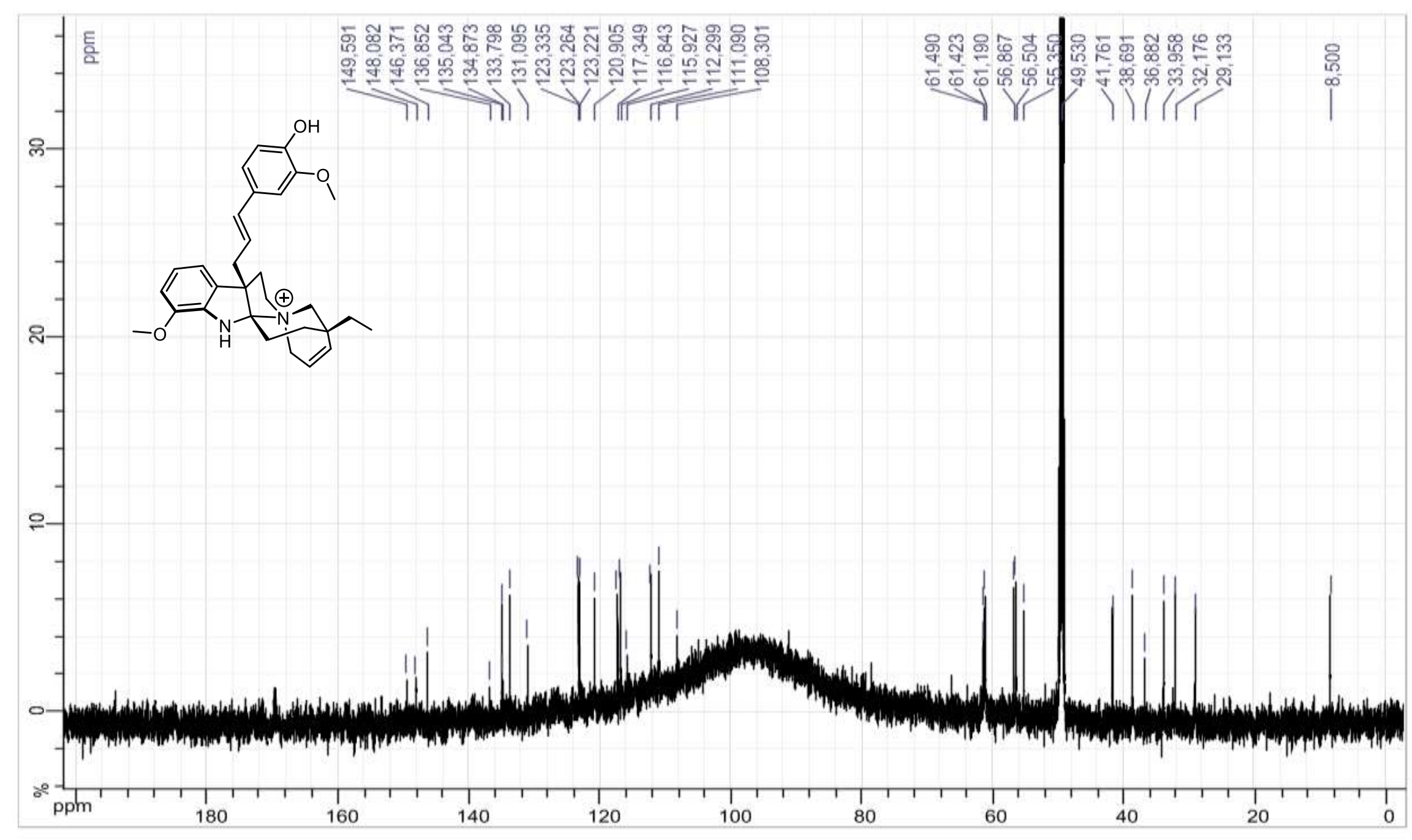


S20. COSY spectrum (600 MHz, MeOH- $\left.d_{4}\right)$ of inaequalisine B (2)

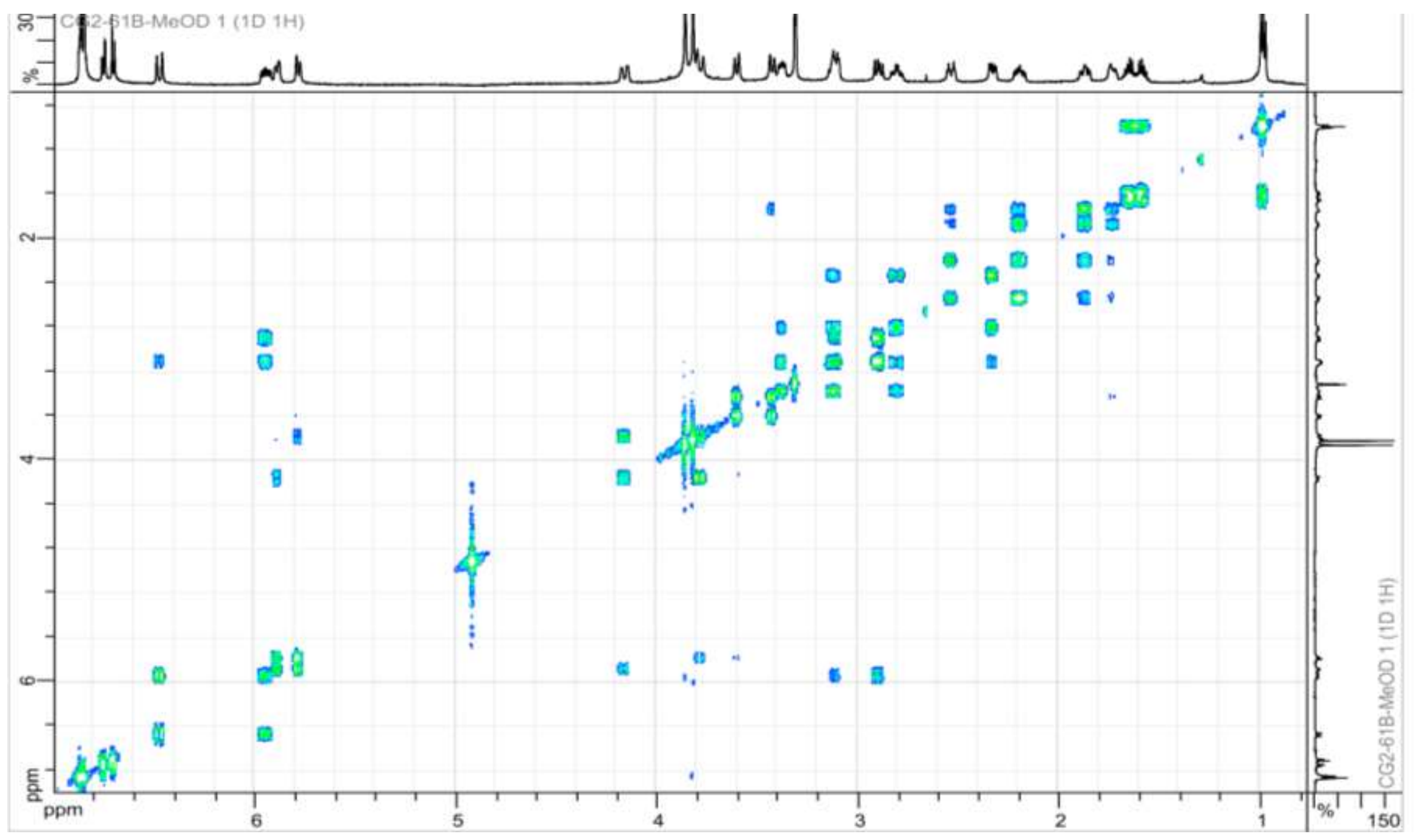


S21. HSQC spectrum (600 MHz, MeOH- $\left.d_{4}\right)$ of inaequalisine B (2)

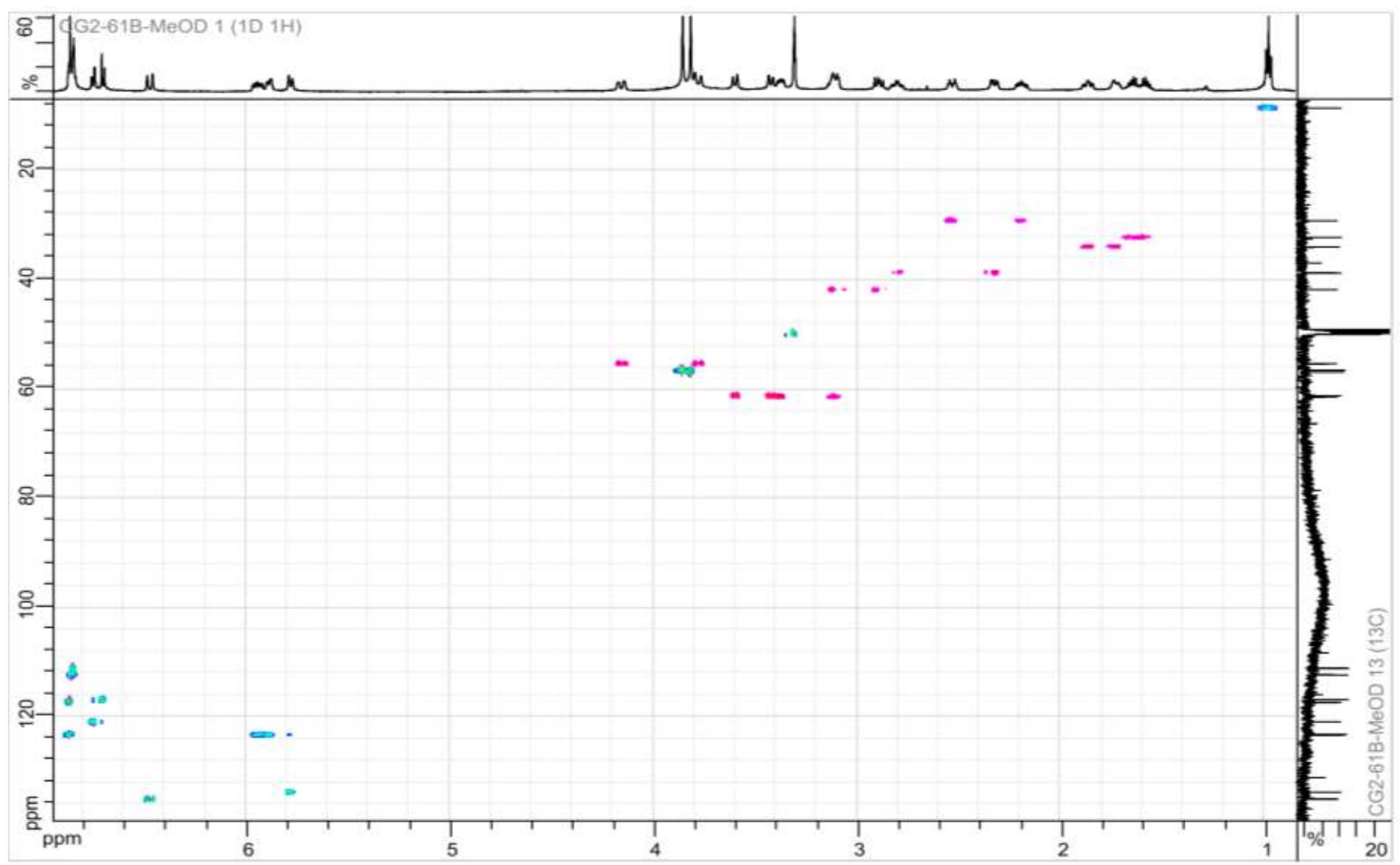


S22. HMBC spectrum (600 MHz, MeOH- $\left.d_{4}\right)$ of inaequalisine B (2)

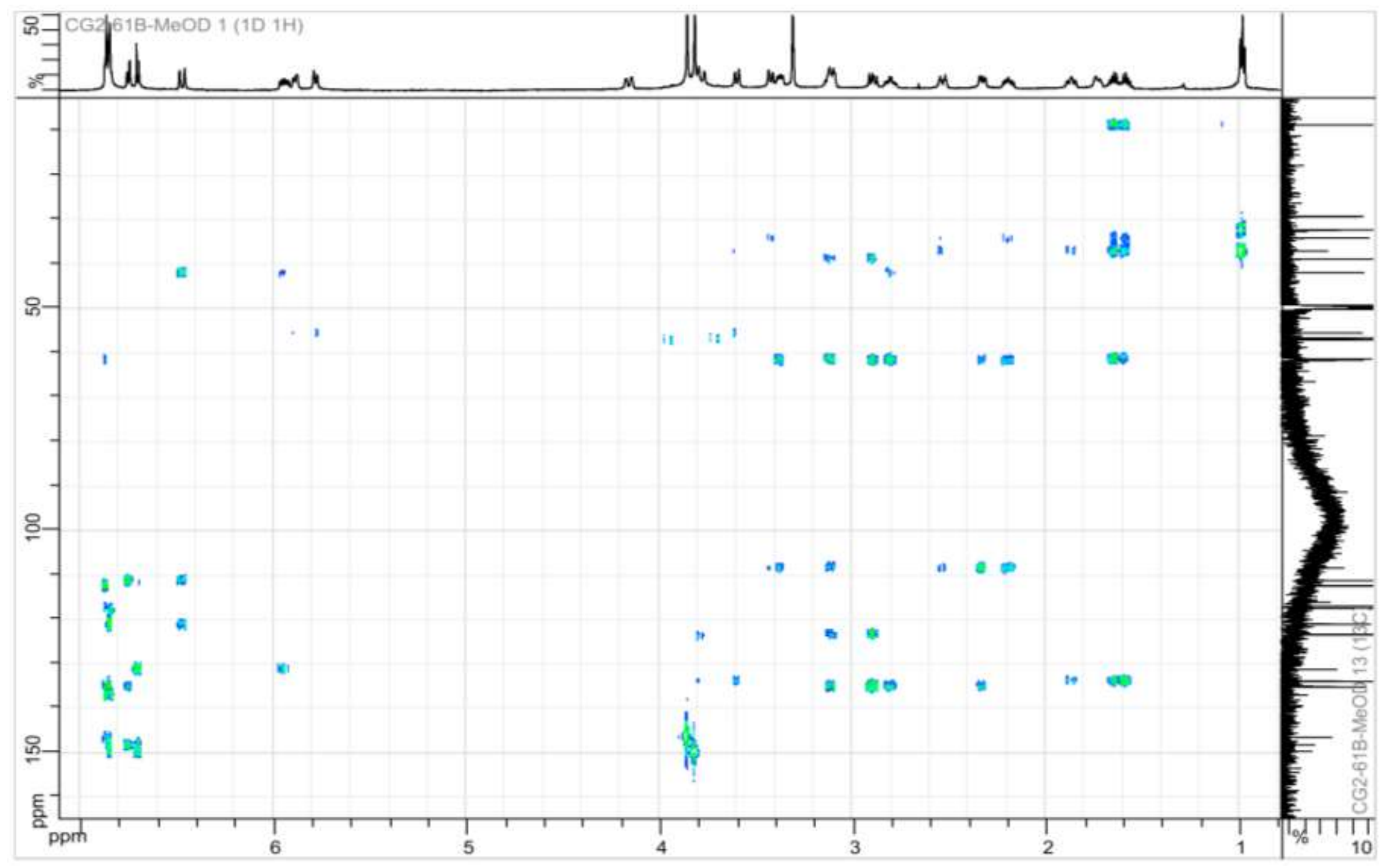


S23. ROESY spectrum (600 MHz, $\left.\mathrm{MeOH}-d_{4}\right)$ of inaequalisine B (2)

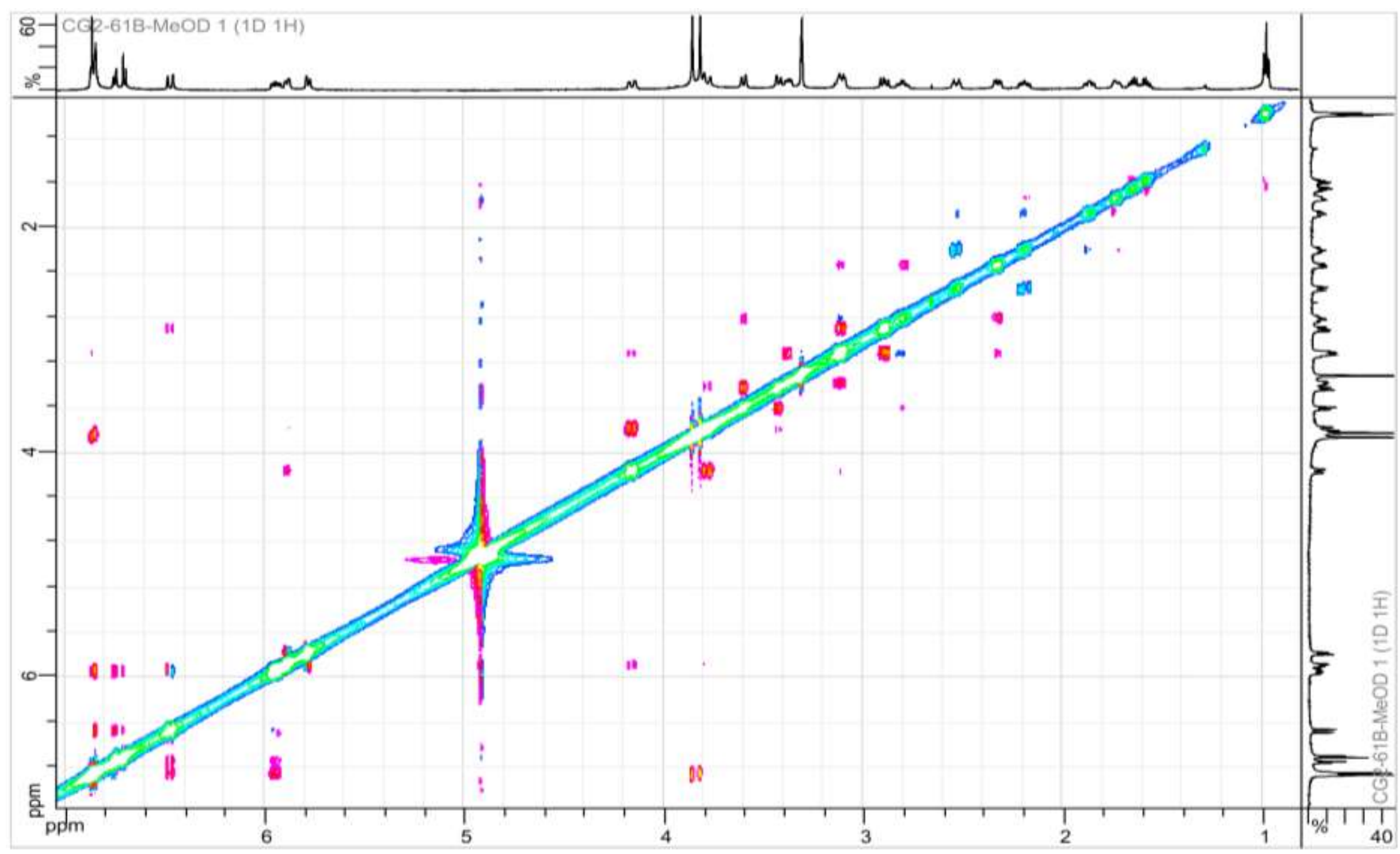




\section{S24. References}

1. Chambers, M. C.; Maclean, B.; Burke, R.; Amodei, D.; Ruderman, D. L.; Neumann, S.; Gatto, L.; Fischer, B.; Pratt, B.; Egertson, J.; Hoff, K.; Kessner, D.; Tasman, N.; Shulman, N.; Frewen, B.; Baker, T. A.; Brusniak, M.-Y.; Paulse, C.; Creasy, D.; Flashner, L.; Kani, K.; Moulding, C.; Seymour, S. L.; Nuwaysir, L. M.; Lefebvre, B.; Kuhlmann, F.; Roark, J.; Rainer, P.; Detlev, S.; Hemenway, T.; Huhmer, A.; Langridge, J.; Connolly, B.; Chadick, T.; Holly, K.; Eckels, J.; Deutsch, E. W.; Moritz, R. L.; Katz, J. E.; Agus, D. B.; MacCoss, M.; Tabb, D. L.; Mallick, P., A cross-platform toolkit for mass spectrometry and proteomics. Nat. Biotechnol. 2012, 30, 918-920.

2. $\quad$ Pluskal, T.; Castillo, S.; Villar-Briones, A.; Orešič, M., MZmine 2: Modular framework for processing, visualizing, and analyzing mass spectrometry-based molecular profile data. $B M C$ Bioinform. 2010, 11, 395.

3. Myers, O. D.; Sumner, S. J.; Li, S.; Barnes, S.; Du, X., One Step Forward for Reducing False Positive and False Negative Compound Identifications from Mass Spectrometry Metabolomics Data: New Algorithms for Constructing Extracted Ion Chromatograms and Detecting Chromatographic Peaks. Anal. Chem. 2017, 89, 8696-8703.

4. $\quad$ Wang, M.; Carver, J. J.; Phelan, V. V.; Sanchez, L. M.; Garg, N.; Peng, Y.; Nguyen, D. D.; Watrous, J.; Kapono, C. A.; Luzzatto-Knaan, T.; Porto, C.; Bouslimani, A.; Melnik, A. V.; Meehan, M. J.; Liu, W.-T.; Crusemann, M.; Boudreau, P. D.; Esquenazi, E.; Sandoval-Calderon, M.; Kersten, R. D.; Pace, L. A.; Quinn, R. A.; Duncan, K. R.; Hsu, C.-C.; Floros, D. J.; Gavilan, R. G.; Kleigrewe, K.; Northen, T.; Dutton, R. J.; Parrot, D.; Carlson, E. E.; Aigle, B.; Michelsen, C. F.; Jelsbak, L.; Sohlenkamp, C.; Pevzner, P.; Edlund, A.; McLean, J.; Piel, J.; Murphy, B. T.; Gerwick, L.; Liaw, C.-C.; Yang, Y.-L.; Humpf, H.-U.; Maansson, M.; Keyzers, R. A.; Sims, A. C.; Johnson, A. R.; Sidebottom, A. M.; Sedio, B. E.; Klitgaard, A.; Larson, C. B.; Boya P, C. A.; Torres-Mendoza, D.; Gonzalez, D. J.; Silva, D. B.; Marques, L. M.; Demarque, D. P.; Pociute, E.; O'Neill, E. C.; Briand, E.; Helfrich, E. J. N.; Granatosky, E. A.; Glukhov, E.; Ryffel, F.; Houson, H.; Mohimani, H.; Kharbush, J. J.; Zeng, Y.; Vorholt, J. A.; Kurita, K. L.; Charusanti, P.; McPhail, K. L.; Nielsen, K. F.; Vuong, L.; Elfeki, M.; Traxler, M. F.; Engene, N.; Koyama, N.; Vining, O. B.; Baric, R.; Silva, R. R.; Mascuch, S. J.; Tomasi, S.; Jenkins, S.; Macherla, V.; Hoffman, T.; Agarwal, V.; Williams, P. G.; Dai, J.; Neupane, R.; Gurr, J.; Rodriguez, A. M. C.; Lamsa, A.; Zhang, C.; Dorrestein, K.; Duggan, B. M.; Almaliti, J.; Allard, P.-M.; Phapale, P.; Nothias, L.-F.; Alexandrov, T.; Litaudon, M.; Wolfender, J.-L.; Kyle, J. E.; Metz, T. O.; Peryea, T.; Nguyen, D.T.; VanLeer, D.; Shinn, P.; Jadhav, A.; Muller, R.; Waters, K. M.; Shi, W.; Liu, X.; Zhang, L.; Knight, R.; Jensen, P. R.; Palsson, B. O.; Pogliano, K.; Linington, R. G.; Gutierrez, M.; Lopes, N. P.; Gerwick, W. H.; Moore, B. S.; Dorrestein, P. C.; Bandeira, N., Sharing and community curation of mass spectrometry data with Global Natural Products Social Molecular Networking. Nat. Biotechnol. 2016, 34, 828-837.

5. Shannon, P.; Markiel, A.; Ozier, O.; Baliga, N. S.; Wang, J. T.; Ramage, D.; Amin, N.; Schwikowski, B.; Ideker, T., Cytoscape: A Software Environment for Integrated Models of Biomolecular Interaction Networks. Genome Res. 2003, 13, 2498-2504.

6. Blei, D. M.; Ng, A. Y.; Jordan, M. I., Latent dirichlet allocation. J. Mach. Learn. Res. 2003, 3, 993-1022.

7. Wandy, J.; Zhu, Y.; van der Hooft, J. J. J.; Daly, R.; Barrett, M. P.; Rogers, S., Ms2lda.org: web-based topic modelling for substructure discovery in mass spectrometry. Bioinformatics 2018, 34, 317-318.

8. Hohenberg, P.; Kohn, W., Inhomogeneous Electron Gas. Physical Review 1964, 136, B864B871. 
9. Kohn, W.; Sham, L. J., Self-Consistent Equations Including Exchange and Correlation Effects. Physical Review 1965, 140, A1133-A1138.

10. Becke, A. D., Density-functional thermochemistry. III. The role of exact exchange. The Journal of Chemical Physics 1993, 98, 5648-5652.

11. Lee, C.; Yang, W.; Parr, R. G., Development of the Colle-Salvetti correlation-energy formula into a functional of the electron density. Physical Review B 1988, 37, 785-789.

12. Wiberg, K. B., Ab Initio Molecular Orbital Theory by W. J. Hehre, L. Radom, P. v. R. Schleyer, and J. A. Pople, John Wiley, New York, 548pp. Price: $\$ 79.95$ (1986). Journal of Computational Chemistry 1986, 7, 379-379.

13. Frisch, M. J. T., H.B.; Schlegel, G.W.; Scuseria, G.E.; Robb, M.A.; Cheeseman, J.R.; Scalmani, G.; Barone, V.; Petersson, G.A.; Nakatsuji, H.; et al. Gaussian 16 Revision B.01; Gaussian Inc.: Wallingford, CT, USA, 2016.

14. Pettersen, E. F.; Goddard, T. D.; Huang, C. C.; Couch, G. S.; Greenblatt, D. M.; Meng, E. C.; Ferrin, T. E., UCSF Chimera-A visualization system for exploratory research and analysis. Journal of Computational Chemistry 2004, 25, 1605-1612.

15. Bruhn, T.; Schaumlöffel, A.; Hemberger, Y.; Bringmann, G., SpecDis: Quantifying the Comparison of Calculated and Experimental Electronic Circular Dichroism Spectra. Chirality 2013, 25, 243-9.

16. Williams, T. K., C., and many others. Gnuplot 4.6: an Interactive Plotting Program. http://gnuplot.sourceforge.net/. 